\title{
HACIA LA EFICIENCIA EN LA GESTIÓN MUNICIPAL
}

\author{
SEALTIEL ÁLVAREZ SÁNCHEZ \\ Universidad Estatal a Distancia, Costa Rica. \\ sealtiels@gmail.com
}

\section{RESUMEN}

La Contraloría General de la República (CGR) diseñó en 2002 una metodología para evaluar la gestión financiera de los gobiernos locales. Más recientemente, en 2012, publicó un modelo actualizado que incluye cinco ejes de la gestión municipal. Esta investigación, de tipo mixto, propone un nuevo modelo de gestión municipal, que permite evaluar la eficiencia de los gobiernos locales con el propósito de promover el desarrollo de la comunidad en nueves áreas: servicios municipales, innovación organizacional, sistema de capacitación municipal, tecnologías de apoyo a la gestión, estrategia municipal, rendición de cuentas y comunicación, administración financiera, promoción de procesos innovadores y uso eficiente de tecnologías de la información. La investigación demostró que la satisfacción de la comunidad, con el actual modelo de gestión, es bajo, principalmente, influenciado por la calidad de los servicios municipales y la inexistencia de un proceso proactivo de rendición de cuentas. El nuevo modelo de gestión, conocido como SISTERA, evalúa la gestión municipal en siete ejes estratégicos: servicios municipales, innovación organizacional, sistema de capacitación municipal y comunal, tecnologías de apoyo a la gestión, estrategia municipal, rendición de cuentas y comunicación y administración de recursos financieros. Mediante 71 indicadores, cualitativos y cuantitativos, se evalúa el trabajo de las municipalidades, ofreciendo recomendaciones para mejorar el desempeño de los gobiernos locales.

PALABRAS CLAVE: DESARROLLO ECONÓMICO, GESTIÓN MUNICIPAL, PLANIFICACIÓN ESTRATÉGICA, PUNTARENAS, SERVICIOS MUNICIPALES, INDICADORES DE GESTIÓN MUNICIPAL.

\section{ABSTRACT}

The Contraloría General de la República (CGR) in 2002 designed a methodology to assess the financial management of local governments. More recently, in 2012, they published an updated model including five areas of municipal management. This research proposes a new model for municipal management designed to measure the efficiency of local governments in order to promote local development in nine areas: municipal services, organizational innovation, municipal training system, IT support management, municipal strategy, accountability and communication, financial management, promotion of innovative processes and efficient use of information technology. This research showed that the community satisfaction with the current management model is low, mainly because of the quality of municipal services and the lack of a proactive process of accountability. The new management model, known as SISTERA, evaluates municipal management in seven strategic areas: municipal services, organizational innovation, municipal training system, and communal technologies to support management, municipal strategy, accountability and communication and management financial resources. The model, composed by 71 indicators (qualitative and quantitative), assesses the work of municipalities, offering recommendations for improving the performance of local governments.

KEYWORDS: ECONOMIC DEVELOPMENT, MUNICIPAL MANAGEMENT, STRATEGIC PLANNING, PUNTARENAS, MUNICIPAL SERVICES, INDICATORS OF MUNICIPAL MANAGEMENT. 


\section{INTRODUCCIÓN}

En Costa Rica, los gobiernos locales han entrado en una nueva etapa, caracterizada por la necesidad de rendir cuentas ante poblaciones más educadas y con mayores expectativas sobre las funciones de la municipalidad. Ante este panorama, el Gobierno Central ha decidido descentralizar algunas de sus funciones hacia los ayuntamientos para fortalecer el papel de estos organismos. Algunas actividades que fueron descentralizadas durante las últimas décadas son: el traslado y gestión del Impuesto de Bienes Inmuebles y el giro de recursos hacia los ayuntamientos para la gestión de la red vial del cantón.

Estas condiciones influyen en la necesidad de mejorar la gobernabilidad y gestión de los gobiernos locales. El abordaje de esta cuestión busca no sólo constituirse en un aporte de corte académico, sino adentrarse en una preocupación práctica para mejorar los estilos de gestión, $y$, en la medida de lo posible, ofrecer una interpretación multidimensional sobre la utilidad de la municipalidad, como medio para mejorar el desarrollo económico del cantón.

El tema de la gestión municipal no ha sido tratado en forma regular en investigaciones científicas, a pesar de la importancia creciente que tienen los ayuntamientos en el establecimiento de estrategias para optimizar el uso de los recursos públicos y coadyuvar, en el largo plazo, con el desarrollo social y económico de las regiones menos favorecidas. Por esta razón, Costa Rica carece de un modelo integral de gestión municipal que permita evaluar la eficiencia de los gobiernos locales. Pocos países en América Latina y el Caribe tienen modelos integrales de gestión con este objetivo. El caso chileno es una excepción (Instituto Chileno de Estudios Municipales, 2009).

Dentro de este contexto, es de especial interés el caso de las municipalidades en la provincia de Puntarenas, pues la misma tiene un perfil socio-económico que la ubican en el último lugar del Índice de Desarrollo Humano, teniendo el segundo indicador más alto en el Índice de Pobreza Humano, solo mejor que el de la provincia de Guanacaste.

Aunque la tasa de desempleo a largo plazo es igual que el promedio del país, comparte con Limón, la expectativa de crecimiento del empleo más baja. Otros indicadores también evidencian rezago, tales como: nivel de electrificación más bajo que el promedio del país, segunda tasa más alta de mortalidad bruta, tercer peor lugar en cantidad de zonas francas y la tasa de robos más alta en Costa Rica por cada 100.000 habitantes. La tabla 1 muestra los indicadores mencionados.

TABLA 1

INDICADORES DE DESARROLLO HUMANO EN COSTA RICA, 2011

\begin{tabular}{|c|c|c|c|c|c|c|c|c|c|c|c|}
\hline \multirow{2}{*}{ 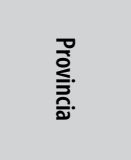 } & \multirow{2}{*}{ 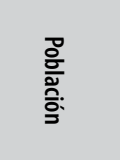 } & \multirow[t]{2}{*}{ IDH } & \multirow[t]{2}{*}{ IPH } & $\begin{array}{l}\text { Desempleo } \\
\text { largo plazo }\end{array}$ & $\begin{array}{l}\text { Expectativas } \\
\text { crecimiento } \\
\text { empleo }\end{array}$ & $\begin{array}{l}\text { Cobertura } \\
\text { eléctrica }\end{array}$ & $\begin{array}{l}\text { Mortalidad } \\
\text { bruta }\end{array}$ & $\begin{array}{l}\text { Zonas } \\
\text { francas }\end{array}$ & EBAIS & Colegios & Robos \\
\hline & & & & \multicolumn{4}{|c|}{ Porcentajes } & \multicolumn{4}{|c|}{ Por cada 100.000 habitantes } \\
\hline San José & 1658075 & 0,75 & 11,92 & $2,4 \%$ & $22,0 \%$ & $100,0 \%$ & $4,33 \%$ & 0,5 & 17,6 & 15,0 & 201,8 \\
\hline Alajuela & 885571 & 0,71 & 13,07 & $2,0 \%$ & $9,0 \%$ & $100,0 \%$ & $4,08 \%$ & 0,6 & 21,7 & 19,1 & 252,0 \\
\hline Cartago & 456329 & 0,77 & 10,77 & $2,5 \%$ & $8,0 \%$ & $100,0 \%$ & $3,70 \%$ & 0,7 & 23,4 & 16,2 & 242,6 \\
\hline Heredia & 515385 & 0,78 & 11,56 & $2,2 \%$ & $15,0 \%$ & $100,0 \%$ & $3,77 \%$ & 2,1 & 16,3 & 14,0 & 160,5 \\
\hline Guanacaste & 280232 & 0,73 & 22,15 & $2,4 \%$ & $11,0 \%$ & $100,0 \%$ & $5,54 \%$ & 0,0 & 31,0 & 28,2 & 479,6 \\
\hline Puntarenas & 368423 & 0,67 & 18,55 & $2,2 \%$ & $7,0 \%$ & $98,0 \%$ & $4,99 \%$ & 0,3 & 30,4 & 30,7 & 573,5 \\
\hline Limón & 451631 & 0,66 & 16,21 & $1,7 \%$ & $7,0 \%$ & $98,0 \%$ & $3,25 \%$ & 0,0 & 25,9 & 18,8 & 334,8 \\
\hline Total & 4615646 & 0,73 & 13,56 & $2,2 \%$ & $13,5 \%$ & $99,6 \%$ & $4,20 \%$ & 0,6 & 21,5 & 18,2 & 270,4 \\
\hline
\end{tabular}

Fuente: Instituto Nacional de Estadísticas y Censos, 2011. 
Como se desprende de los indicadores de la Tabla 1, es importante identificar oportunidades para favorecer el desarrollo económico de la provincia de Puntarenas. A nivel de Gobierno Central se han realizado algunos esfuerzos con este objetivo. Por ejemplo, esta provincia tiene más colegios per cápita que las demás (30,7 colegios por cada 100.000 habitantes). Sin embargo, el impacto de este esfuerzo sobre otros indicadores del desarrollo humano es limitado. En ese contexto, esta investigación es de ayuda para determinar cómo los gobiernos locales pueden influir de forma más directa en el desarrollo económico de los cantones puntarenenses.

\section{Importancia de la gestión municipal}

Desde la década del 90 Costa Rica inició un proceso de descentralización de las funciones del Gobierno Central hacia los gobiernos locales. La trascendencia de las decisiones municipales ha aumentado como resultado de esta transformación estructural. Sin embargo, a pesar de la importancia creciente de los ayuntamientos, no existen modelos integrales de gestión que sirvan para medir la eficiencia operativa de las municipalidades.

Se ha intentado compensar la carencia de un modelo integral, mediante el desarrollo de modelos específicos, que miden la eficiencia desde el punto de vista financiero. Tal es el caso del modelo de gestión municipal de la Contraloría General de la República (CGR). Sin embargo, no todos los aspectos del quehacer municipal son evaluados mediante este indicador. Entre las áreas que están excluidas del modelo de la CGR están: liderazgo, procesamiento y análisis de información, relación con los usuarios y calidad de la prestación de servicio. La omisión de estas áreas, es una importante limitación para evaluar desde una perspectiva integral el trabajo de los ayuntamientos (Contraloría General de la República, 2009).

La imposibilidad para determinar la eficiencia del trabajo de las municipalidades, tiene influencia, en el largo plazo, en el desarrollo económico y social de las comunidades. Varios autores, tales como
Asencio (2006), Moreno (2001) y Pérez (2007) establecen una correlación entre la labor municipal y el desarrollo regional. Estos autores, entre otros, establecen la gestión municipal eficiente, como una condición necesaria (aunque no suficiente) para el desarrollo de una región. A esta variable se pueden sumar otras de naturaleza exógenas, que, en el largo plazo, promueven o retrasan el desarrollo socioeconómico de una región. Entre las condiciones exógenas que influyen en el desarrollo están aquellas de tipo económico, tecnológico, sociocultural, político y ambiental (Araujo, 2009).

Por lo tanto, ante la necesidad de fortalecer el desarrollo de una provincia como Puntarenas, es necesario disponer de un modelo integral de gestión municipal, que permita evaluar el trabajo del gobierno local y determinar la influencia del mismo sobre algunos indicadores, tales como el Índice de Desarrollo Humano.

\section{METODOLOGÍA DE INVESTIGACIÓN}

La investigación se realizó en los once cantones de la provincia de Puntarenas, que suman un total de 368.423 habitantes, según el último estudio del Instituto Nacional de Estadística y Censos (INEC), realizado en el año 2011. Como se ha analizado, estas comunidades comparten características similares, tales como: altas tasas de desempleo y pocas zonas francas que ayuden a propiciar el crecimiento económico.

La recolección de información se realizó mediante fuentes primarias y secundarias. Para recoger la información primaria se aplicaron dos cuestionarios: uno a los alcaldes de las municipalidades y otro a una muestra seleccionada de la población de cada cantón. Para elegir la muestra se utilizó un nivel de confianza del 95\% y un error estadístico del 4,78\%. Estos parámetros incrementan el nivel de precisión de la investigación incluso por encima de estudios similares que utilizan errores estadísticos del 5\%. 
Para obtener el tamaño de la muestra, se utiliza la fórmula de Balestrini para poblaciones finitas. El tamaño de la misma es de 420 individuos, que están distribuidos siguiendo los mismos criterios demográficos (lugar de residencia y género) de la provincia de Puntarenas. Dentro de cada segmento, los entrevistados se eligieron en forma aleatoria simple y se entrevistaron en sus casas de habitación o sitios públicos, tales como: parques, iglesias y paradas de autobuses.

La investigación es de tipo mixto y transversal. Se evalúan dos hipótesis relacionadas con la gestión municipal y el desarrollo local. La primera hipótesis, que se acepta parcialmente, se prueba mediante un modelo de regresión y establece una relación positiva entre el desarrollo económico y la gestión municipal. La segunda hipótesis se prueba mediante una tabla de correlaciones, utilizando el coeficiente de Spearman. Esta establece una relación entre el desarrollo local y la satisfacción de la comunidad con el modelo de gestión municipal. También se acepta en forma parcial.

Durante el proceso de investigación se siguieron los pasos del método científico: formulación del problema, identificación de factores principales, formulación de hipótesis, comprobación de la hipótesis, reconsideración de la teoría y presentación de resultados. Con el propósito de mantener la validez externa del experimento, se evitó someter a los sujetos a factores condicionantes, tales como: respuestas inducidas, escalas de medición sin validez científica o influencia política. Con el mismo propósito también se eligió la muestra utilizando criterios estadísticos. Estas características permiten extender, mediante un proceso de generalización, el alcance del estudio a otras esferas geográficas.

Este proceso de generalización también se puede aplicar a municipalidades de otras provincias, que tienen problemas similares, relacionados con la gestión municipal. El Instituto de Fomento y Asesoría Municipal (IFAM), con base en estudios de la Contraloría General de la República
(CGR), ha indicado que, los gobiernos locales costarricenses tienen desafíos comunes, tales como: baja ejecución del gasto presupuestado, bajo cumplimiento de las metas programadas, procesos de planificación incipientes, limitada participación popular, débil manejo de los ingresos propios, poca integración entre los departamentos de los gobiernos locales y recursos humanos con problemas de capacitación. También un informe del Banco Interamericano de Desarrollo (BID) señaló que, con pocas excepciones, las municipalidades de Costa Rica no tienen sistemas integrados de apoyo a la gestión ni procesos formales para promover la innovación tecnológica (Aguilar, 2009).

Las fuentes anteriormente citadas confirman que los gobiernos locales costarricenses tienen problemas comunes. Por lo tanto, los resultados del estudio se puedan extender a otros ayuntamientos, que tengan características similares a la población investigada. Es posible teorizar, con base en los indicadores de desarrollo humano (que se analizaron al inicio de este capítulo) que el beneficio del estudio puede ser mayor para provincias como Limón y Guanacaste, que tienen indicadores de desarrollo similares a Puntarenas. El uso y aplicación extendida del modelo requiere de un proceso de revisión y homologación que es posible desarrollar en investigaciones posteriores.

\section{MODELO ACTUAL DE GESTIÓN MUNICIPAL EN PUNTARENAS}

Durante la investigación se demuestra que la provincia de Puntarenas tiene un atraso importante en el desarrollo de programas para promover la innovación a nivel de gobiernos locales. Los ejemplos de ideas innovadoras son escasos y limitados a situaciones específicas. Tal es el caso de los programas nocturnos de recolección de basura o aseo urbano que se desarrollan en el cantón de Golfito o del modelo de comunicación municipal que tiene la municipalidad de Parrita. 
La mayoría de los gobiernos locales de esta provincia no realizan una gestión centrada en el contribuyente como eje del proceso. Muestra de ello es la inexistencia de encuestas de satisfacción, así como su estructura organizacional, que, en general, no tiene Contralorías de Servicio ni Oficinas de Información para el contribuyente.

El modelo de gestión municipal también evidencia carencias relacionadas con el reclutamiento, selección y capacitación de los funcionarios municipales. No existen programas robustos de mejoramiento continúo ni procesos de evaluación para el personal de los gobiernos locales. Las opciones de capacitación que se ofrecen son limitadas, tanto dentro de la municipalidad como en la comunidad. No hay procesos articulados consistentes que permitan ofrecer alternativas educativas de calidad. La coordinación con instituciones educativas, públicas o privadas, y otras instituciones del Estado es reducida, y generalmente se limita a unos pocos cursos que ofrece el Ministerio de Economía, Industria y Comercio o el Instituto de Fomento y Asesoría Municipal.

En relación con la planeación estratégica, se determinó que todos los ayuntamientos tienen planes maestros. Sin embargo, en algunos casos están desactualizados, no tienen un seguimiento adecuado o fueron creados sin la participación popular. Al analizar cuatro áreas fundamentales para el desarrollo local (educación, agricultura, salud y seguridad) se evidenció que las municipalidades no tienen políticas consistentes para promover el mejoramiento de estos sectores. En la mayoría de los casos, las actividades realizadas en estos ejes estratégicos son específicas o requeridas por ley. Tal es el caso de los programas de fumigación y las contribuciones económicas a las Juntas de Educación.

La administración de los recursos financieros está regida por las leyes y reglamentos aplicables a estas organizaciones públicas. El ambiente de control se limita a los aspectos básicos exigidos por la legislación y son pocas las acciones que se toman para mejorarlo o extenderlo. Una condición que empeora esta situación es la inconsistencia en los procedimientos para denunciar actos de corrupción. En algunos casos no existen órganos independientes que atiendan las denuncias y aseguren el debido proceso de las mismas. Es común que las denuncias sean atendidas por los jefes de departamento o por el alcalde de la municipalidad.

Asimismo, la calidad de los servicios municipales es un aspecto débil de la gestión municipal en Puntarenas. En general, la calidad de los servicios no está acreditada por organismos reconocidos. La única excepción es el mantenimiento de caminos y vías públicas, cuya calidad se revisa a través de la Unidad Técnica Vial de cada gobierno local.

El proceso de rendición de cuenta es heterogéneo y el único método que se utiliza en forma consistente son las sesiones del Concejo Municipal. Aunque la información está disponible a la comunidad (en razón de la naturaleza misma de las municipalidades), en general, no se realizan esfuerzos continuos y eficientes con el propósito de informar al contribuyente del accionar del gobierno local.

La investigación permite establecer que el actual modelo de gestión de las municipalidades puntarenenses tiene deficiencias en las siguientes áreas:

- Generación y fortalecimiento de la innovación institucional.

- Procesos de capacitación para los funcionarios del gobierno local y las comunidades.

- Desarrollo de planes estratégicos integrados, coordinados y eficientes en las siguientes áreas prioritarias: salud, educación, agricultura y seguridad.

- Promoción de un adecuado y sano ambiente de control interno.

- Acreditación de la calidad de los servicios municipales.

- Comunicación y proyección comunal. 


\section{Percepción del modelo de gestión municipal en Puntarenas}

La satisfacción de la población con el actual modelo de gestión municipal en la provincia de Puntarenas es moderada. Aproximadamente la mitad de la población, a saber, el 55,2\% está medianamente satisfecha con la gestión de los gobiernos locales. Un 24,5\% está muy satisfecho y el restante 20,2\% tiene un alto grado de insatisfacción.

La investigación utiliza una matriz de componentes principales rotados Varimax para reducir el número de variables y encontrar la estructura subyacente de los datos. Mediante este análisis se crearon dos variables nuevas, denominadas factores, que explican el nivel de insatisfacción de la población con el modelo de gestión municipal vigente. Estos factores son:

- Componente 1 - Eficiencia de la comunicación municipal: incluye comunicación municipal, uso de foros comunales, uso de perifoneo, uso de volantes, entrevistas del alcalde en medios de comunicación y rendición de cuentas.

- Componente 2 - Atención al público: integrada por actitud para atender al público, rapidez en los trámites municipales y frecuencia con que se recibe un buen servicio.

Como se ha indicado, las principales variables que influyen en la percepción del modelo de gestión municipal están relacionadas con el sistema de comunicación municipal y el servicio al contribuyente. Por lo tanto es necesario que el modelo de gestión incluya mediciones específicas para estos componentes.

Para investigar la percepción de calidad del sistema de gestión municipal se utiliza un análisis correlacional (utilizando el coeficiente de correlación de Spearman). Este examen asocia el concepto de calidad con las siguientes variables: calidad general de los servicios ofrecidos al contribuyente $(r=0,395)$; eficiencia de la comuni- cación municipal ( $r=0,223$ ); uso eficiente de recursos financieros $(r=0,181)$ y el estado de las calles $(r=0,180)$. Por lo tanto, el manejo adecuado de estas condiciones es fundamental, para promover el concepto de calidad de la gestión municipal, en la población. En todos los casos la correlación fue altamente significativa, con un nivel de significancia de $1 \%$.

El servicio al cliente también se investigó siguiendo el mismo análisis descrito en el párrafo anterior. Como resultado, se determinó que el concepto se asocia positivamente con las siguientes variables: percepción sobre el buen uso de los recursos financieros $(r=0,230)$; calidad general de los servicios que ofrece la municipalidad ( $r=0,216)$; estado de las calles $(r=$ $0,213)$ y la calidad del servicio de agua potable $(r$ $=0,126$ ). Estas correlaciones también tienen un nivel de significancia del 1\%, por lo que constituyen conclusiones válidas del estudio.

La mayoría de la población, representada por un $72,7 \%$, no conoce el plan estratégico del gobierno local. De aquellos que indican conocerlo, un 71,44\% afirma que el mismo tiene poca o moderada utilidad para promover el desarrollo del cantón. Solo el 29,29\% de quienes conocen el plan estratégico concuerdan en que el modelo estratégico del municipio es adecuado. Como resultado, se infiere la importancia de involucrar a la comunidad en el proceso de planeación estratégica y realizar mejoras en el proceso de comunicación con la comunidad.

Otro campo en que la población tiene una opinión desfavorable de los gobiernos locales está relacionado con los programas de capacitación para la comunidad. El 94,05\% de los entrevistados afirma no haber participado en ningún proceso educativo que haya sido el resultado de la coordinación de la municipalidad con otras instituciones o que estuviera patrocinado por el ayuntamiento.

Con base en el análisis anterior, se calculó un índice compuesto para medir la satisfacción con la gestión de los gobiernos locales. El promedio 
de la provincia de Puntarenas es del 36,95\%. Ningún cantón alcanza un nivel de satisfacción mayor que el 57,69\% (que es el máximo alcanzado por la Municipalidad de Montes de Oro). El gobierno local con el menor índice de satisfacción es Osa, con un 32,69\%.

En conclusión, según la opinión de la comunidad, puede indicarse que todos los gobiernos locales investigados tienen deficiencias en la gestión municipal. Con base en estos resultados, se determina necesaria la inclusión de los siguientes componentes en el modelo de gestión integral:

- Servicio y atención al contribuyente.

- Sistema de rendición de cuentas y uso de recursos públicos.

- Calidad de los servicios municipales.

- Comunicación comunal.

- $\quad$ Sistema de capacitación a funcionarios municipales y la comunidad.

- Desarrollo de planes estratégicos.

En consecuencia, es necesario que las municipalidades trabajen en los siguientes ejes estratégicos para mejorar la gestión municipal: planeación estratégica, relación con los usuarios de servicios, información, comunicación y análisis, sistema de capacitación municipal, prestación de servicios y uso eficiente de los recursos financieros y materiales.

\section{EL MODELO SISTERA}

El modelo de gestión municipal propuesto es el resultado del análisis e identificación de áreas prioritarias que deben considerarse para promover la eficiencia de la gestión municipal. Este modelo se denomina SISTERA e incluye los siguientes ejes estratégicos que se muestran en la figura 1.

Estos ejes incluyen indicadores para todas las áreas identificadas como prioritarias durante el proceso de análisis. Estas áreas son:

1. Prestación de servicios municipales y servicio al contribuyente.

2. Opciones de capacitación para funcionarios municipales y para la comunidad.

3. Planeación estratégica.

4. Sistema de comunicación municipal y rendición de cuentas.

5. Gestión de recursos financieros y materiales.

También se incluyen dos áreas adicionales, que se consideran necesarias, para favorecer la gestión

\section{EJES ESTRATÉGICOS DEL MODELO SISTERA}

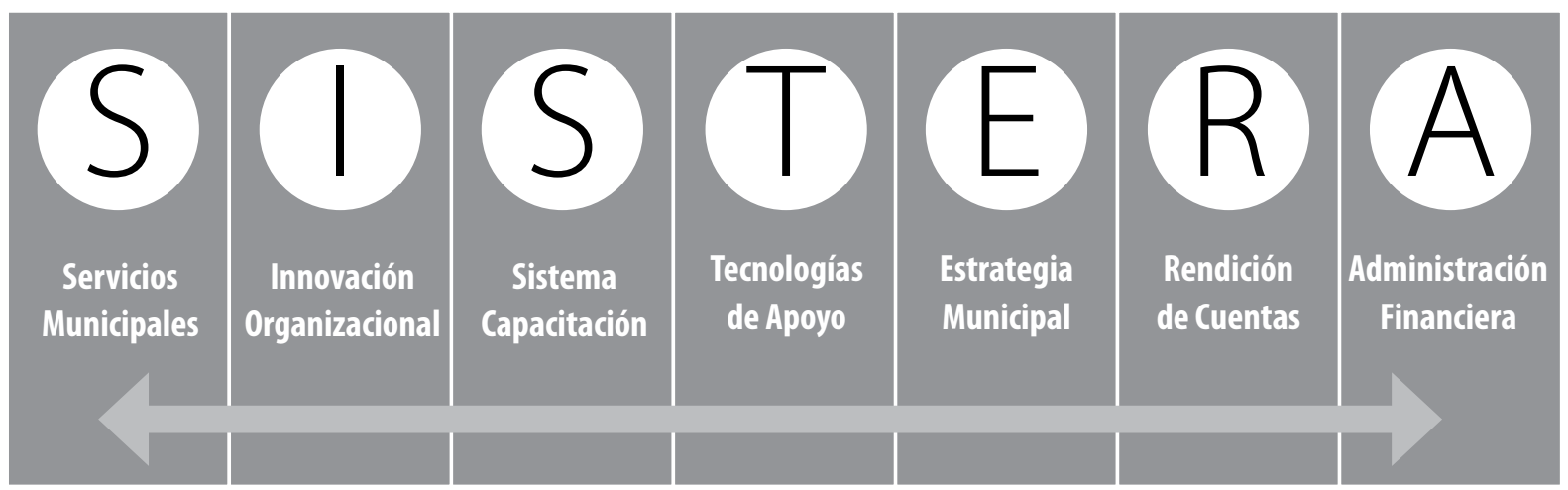

Fuente: Elaboración propia, 2012. 
eficiente del trabajo municipal. Estas áreas son: la innovación y el uso eficiente de las tecnologías de la información (Escorsa, 2003). El uso de estos siete pilares fundamentales permite aplicar el modelo, con pocos cambios, en otras regiones que tengan características similares a la población investigada y cuyos gobiernos locales deseen promover la eficiencia de la gestión (Hinojosa, 2006).

Conceptualmente el modelo se representa, en forma resumida, mediante la figura 2.

El modelo SISTERA, tiene cuatro ambientes principales, que incorporan variables endógenas y exógenas. Las cuatro áreas del modelo son:

- Macro entorno: que incluye variables de tipo social, económico, ambiental, cultural y político.

- Entorno tecnológico y de procesos: se ha separado del macro entorno general dos variables: la innovación y la tecnología, dada la importancia que estas tienen para el trabajo de las municipalidades.

- Entorno institucional: con variables como planeación estratégica, gestión financiera y capacitación.
- Entorno comunal: que comprende la prestación de servicios y la rendición de cuentas.

SISTERA es un modelo integral, porque considera los siete ejes estratégicos antes citados, agrupados en cuatro áreas o ambientes principales. A partir de esta concepción se definen los indicadores cuantitativos y cualitativos de medición.

\section{Indicadores cuantitativos}

Se utilizan indicadores cuantitativos para evaluar la gestión municipal en las siguientes áreas: servicios municipales, innovación organizacional, sistema de capacitación municipal, tecnologías de apoyo a la gestión, rendición de cuentas y comunicación, estrategia municipal y administración de los recursos financieros. En total, hay 71 indicadores cuantitativos.

Los indicadores cuantitativos se dividen en siete áreas: servicios municipales, innovación organizacional, sistema de capacitación municipal y comunal, tecnologías de apoyo a la gestión, estrategia municipal, rendición de cuentas y comunicación y administración de recursos financieros. El peso de cada grupo de indicadores se indica en la tabla 2.

RESUMEN DEL MODELO “SISTERA” DE GESTIÓN MUNICIPAL

\section{MACRO ENTORNO}

\section{Entorno institucional}

Planificación

Gestión Financiera

Capacitación

\section{Entorno comunal}

Rendición de cuentas

Servicios Municipales

\section{Tecnología e innovación}


TABLA 2

\section{PESO DE CADA INDICADOR CUANTITATIVO EN EL MODELO SISTERA}

\begin{tabular}{|l|c|}
\hline \multicolumn{1}{|c|}{ Grupo } & Peso relativo \\
\hline Servicios municipales & $15 \%$ \\
\hline Innovación organizacional & $14 \%$ \\
\hline Sistema de capacitación municipal y comunal & $14 \%$ \\
\hline Tecnologías de apoyo a la gestión & $14 \%$ \\
\hline Estrategia municipal & $14 \%$ \\
\hline Rendición de cuentas y comunicación & $15 \%$ \\
\hline Administración de recursos financieros & $14 \%$ \\
\hline Total & $100 \%$ \\
\hline
\end{tabular}

Fuente: Elaboración propia, 2012.
Se asigna un peso, ligeramente mayor, a los servicios municipales; ya que, según el estudio realizado este tiene una influencia directa sobre la percepción de eficiencia en la gestión del gobierno local. También, el grupo de indicadores relacionados con la comunicación tienen un peso mayor considerando los resultados del estudio factorial.

A cada indicador se le asigna un nivel de gestión: básico, intermedio o avanzado, con base en los criterios indicados en el Anexo 1. El cálculo de cada indicador y su ponderación se muestran en la tabla 3.

\section{CÁLCULO DEL INDICADOR CUANTITATIVO DE GESTIÓN MUNICIPAL}

\begin{tabular}{|c|c|c|c|c|c|c|}
\hline Áreas e indicadores & Razones para cálculo & $\begin{array}{l}\% \\
/ 1\end{array}$ & 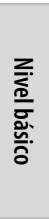 & 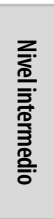 & 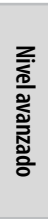 & 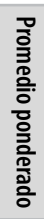 \\
\hline \multicolumn{7}{|l|}{ (S)ervicios municipales (15\%) } \\
\hline \#1 Inversión aseguramiento calidad & $\frac{\text { Gasto programa aseguramiento calidad }}{\text { Total del gasto }}$ & $9 \%$ & & & & \\
\hline \#2 Inversión aplicaciones ventanilla & $\frac{\text { Gasto aplicaciones de ventanilla }}{\text { Total del gasto }}$ & $9 \%$ & & & & \\
\hline \#3 Satisfacción del contribuyente & $\frac{\text { Usuarios satisfechos con servicios municipales }}{\text { Total de usuarios entrevistados }}$ & $10 \%$ & & & & \\
\hline $\begin{array}{l}\text { \#4 Tiempo respuesta atención quejas, peticiones y } \\
\text { reclamos }\end{array}$ & $\frac{\text { Tiempo total usado en atender quejas, peticiones y reclamos }}{\text { Total de quejas, peticiones y reclamos }}$ & $9 \%$ & & & & \\
\hline \#5 Exactitud cobro servicios & $\frac{\text { Total anual servicios cobrados de forma correcta }}{\text { Total anual de cobros de servicios realizados }}$ & $9 \%$ & & & & \\
\hline \#6 Disponibilidad de servicios municipales & $\frac{\text { Promedio de disponibilidad de cada servicio municipal en horas }}{\text { Total de servicios municipales ofrecidos }}$ & $9 \%$ & & & & \\
\hline \#7 Tiempo espera para ser atendido & $\frac{\text { Tiempo promedio de espera por servicio }}{\text { Total de servicios municipales ofrecidos }}$ & $9 \%$ & & & & \\
\hline \#8 Ayuda social a grupos vulnerables & $\frac{\text { Gasto en ayudas sociales a grupos socialmente vulnerables }}{\text { Total del gasto }}$ & $9 \%$ & & & & \\
\hline \#9 Gasto en limpieza y ornato del cantón & $\frac{\text { Gastos de limpieza y ornato del cantón }}{\text { Total del gasto }}$ & $9 \%$ & & & & \\
\hline \#10 Gasto en servicios de seguridad ciudadana & $\frac{\text { Gastos en seguridad ciudadana }}{\text { Total del gasto }}$ & $9 \%$ & & & & \\
\hline $\begin{array}{l}\text { \#11 Población cubierta por servicio recolección de } \\
\text { desechos sólidos }\end{array}$ & $\frac{\text { Poblados donde se presta el servicio de recolección de desechos sólidos }}{\text { Total de poblados del cantón }}$ & $9 \%$ & & & & \\
\hline
\end{tabular}




\begin{tabular}{|c|c|c|c|c|c|c|}
\hline Áreas e indicadores & Razones para cálculo & $\begin{array}{l}\% \\
/ 1\end{array}$ & 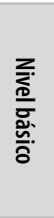 & 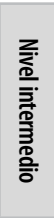 & 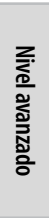 & 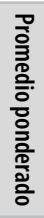 \\
\hline \multicolumn{7}{|l|}{ (I)nnovación organizacional (14\%) } \\
\hline \#12 Horas por funcionario dedicado a innovación & $\frac{\text { Total de horas anuales dedicadas a trabajar en actividades de innovación }}{\text { Cantidad de funcionarios municipales }}$ & $9 \%$ & & & & \\
\hline $\begin{array}{l}\text { \#13 Inversión en bienes que implican cambio tec- } \\
\text { nológico }\end{array}$ & $\begin{array}{l}\frac{\text { Total de gasto en bienes de capital que impliquen cambio tecnológico }}{\text { Total del gasto }} \\
\text { The }\end{array}$ & $9 \%$ & & & & \\
\hline \#14 Inversión en modernización organizacional & $\begin{array}{l}\text { Total de gasto en actividades de modernización organizacional } \\
\text { Total del gasto }\end{array}$ & $9 \%$ & & & & \\
\hline \#15 Inversión en modernización de procesos & $\frac{\text { Total de gasto en actividades de modernización de procesos }}{\text { Total del gasto }}$ & $9 \%$ & & & & \\
\hline $\begin{array}{l}\text { \#16 Alianzas con organizaciones que promueven } \\
\text { innovación }\end{array}$ & Total de alianzas con organismos que promueven la innovación & $9 \%$ & & & & \\
\hline \#17 Iniciativas presentadas sobre innovación & $\frac{\text { Iniciativas recibidas que impliquen innovación procesos u organización }}{\text { Total de iniciativas recibidas }}$ & $9 \%$ & & & & \\
\hline \#18 Iniciativas aprobadas sobre innovación & $\frac{\text { Iniciativas aprobadas implementadas que impliquen innovación }}{\text { Total iniciativas recibidas que impliquen innovación }}$ & $10 \%$ & & & & \\
\hline \#19 Proyectos activos sobre innovación & Total proyectos activos sobre innovación & $9 \%$ & & & & \\
\hline $\begin{array}{l}\text { \#20 Funcionarios matriculados en cursos de inno- } \\
\text { vación }\end{array}$ & $\frac{\text { Total anual de uncionarios matriculados en cursos de innovación }}{\text { Total de funcionarios municipales }}$ & $9 \%$ & & & & \\
\hline \multicolumn{7}{|c|}{ (S)istema de capacitación municipal y comunal (14\%) } \\
\hline \#21 Horas capacitación por funcionario & $\frac{\text { Total anual de horas de capacitación a funcionarios municipales }}{\text { Total de funcionarios municipales }}$ & $8 \%$ & & & & \\
\hline \#22 Horas capacitación por cada 10.000 habitantes & $\frac{\text { Total anual de horas de capacitación a la comunidad }}{\text { Total de habitantes del cantón /10 } 000}$ & $8 \%$ & & & & \\
\hline \#23 Alianzas con instituciones educativas & Total de alianzas con instituciones educativas & $8 \%$ & & & & \\
\hline \#24 Presupuesto dedicado a capacitación funcionarios & $\frac{\text { Total de gasto dedicado a actividades de capacitación de funcionarios }}{\text { Total de Gasto }}$ & $9 \%$ & & & & \\
\hline \#25 Presupuesto dedicado a capacitación comunal & $\frac{\text { Total gasto dedicado a actividades de capacitación comunidad }}{\text { Total de gasto }}$ & $9 \%$ & & & & \\
\hline \#26 Satisfacción funcionario por capacitación recibida & $\begin{array}{l}\text { Funcionarios satisfechos con capacitación recibida } \\
\text { Total de funcionarios municipales que recibieron capacitación }\end{array}$ & $9 \%$ & & & & \\
\hline \#27 Satisfacción comunal por capacitación recibida & $\underline{\text { Participantes satisfechos con capacitación recibida }} \underset{\text { Total participantes municipales que recibieron capacitación }}{ }$ & $9 \%$ & & & & \\
\hline \#28 Cursos abiertos y cerrados por habitante & $\frac{\text { Cursos (mínimo } 8 \text { horas) abiertos y terminados satisfactoriamente }}{\text { Total de población del cantón/10000 }}$ & $8 \%$ & & & & \\
\hline \#29 Funcionarios con grado de bachiller universitario & $\frac{\text { Funcionarios con grado mínimo de bachiller universitario }}{\text { Total de funcionarios municipales }}$ & $8 \%$ & & & & \\
\hline \#30 Funcionarios con grado de licenciado o máster & $\frac{\text { Funcionarios con grado mínimo de licenciado o máster }}{\text { Total de funcionarios municipales }}$ & $8 \%$ & & & & \\
\hline \#31 Funcionarios que reciben becas de estudio & $\frac{\text { Funcionarios que reciben una beca o ayuda al estudio }}{\text { Total de funcionarios municipales }}$ & $8 \%$ & & & & \\
\hline \#32 Habitantes que reciben becas de estudio & $\frac{\text { Personas que reciben una beca } 0 \text { ayuda al estudio }}{\text { Total de habitantes del cantón/10 } 000}$ & $8 \%$ & & & & \\
\hline
\end{tabular}




\begin{tabular}{|c|c|c|c|c|c|c|}
\hline Áreas e indicadores & Razones para cálculo & $\begin{array}{l}\% \\
/ 1\end{array}$ & 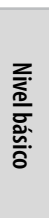 & 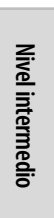 & 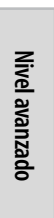 & 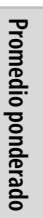 \\
\hline \multicolumn{7}{|l|}{ (T)ecnologías de apoyo a la gestión (14\%) } \\
\hline $\begin{array}{l}\text { \#33 Cumplimiento programas mantenimiento } \\
\text { equipos }\end{array}$ & $\begin{array}{l}\text { Programas anuales de mantenimiento ejecutados } \\
\text { Programas anuales de mantenimiento programados }\end{array}$ & $10 \%$ & & & & \\
\hline \#34 Inversión en tecnología & $\frac{\text { Gastos en hardware + gastos en software }}{\text { Total de gasto }}$ & $10 \%$ & & & & \\
\hline \#35 Computadoras por funcionario & $\frac{\text { Total de computadoras funcionales }}{\text { Total de funcionarios municipales }}$ & $10 \%$ & & & & \\
\hline \#36 Funcionarios con acceso a email e Internet & $\begin{array}{l}\frac{\text { Funcionarios con acceso a internet y email }}{\text { Total de funcionarios municipales }} \\
\text {. }\end{array}$ & $10 \%$ & & & & \\
\hline \#37 Trámites realizados por página web & $\frac{\text { Trámites anuales realizados mediante la página web }}{\text { Total de transacciones anuales realizadas }}$ & $10 \%$ & & & & \\
\hline \#38 Trámites disponibles en línea & $\frac{\text { Total de trámites que están disponibles en línea }}{\text { Total de trámites que ofrece la municipalidad }}$ & $10 \%$ & & & & \\
\hline \#39 Procesos municipales soportado por las TICs & $\frac{\text { Total de procesos internos soportados por las TIC }}{\text { Total de procesos internos }}$ & $10 \%$ & & & & \\
\hline \#40 Centros inteligentes por cada 10.000 habitantes & $\frac{\text { Cantidad de centros comunitarios inteligentes }}{\text { Total población del cantón/ } 10000}$ & $10 \%$ & & & & \\
\hline \#41 Alfabetismo tecnológico de funcionarios & $\frac{\text { Funcionarios con nivel satisfactorio de alfabetismo tecnológico }}{\text { Total de funcionarios municipales }}$ & $10 \%$ & & & & \\
\hline $\begin{array}{l}\text { \#42 Funcionarios que trabajan en el Departamento } \\
\text { de TIC }\end{array}$ & $\begin{array}{l}\text { Funcionarios que trabajan en el departamento de las TICS } \\
\text { Total de computadoras funcionales en la municipalidad / } 50\end{array}$ & $10 \%$ & & & & \\
\hline \multicolumn{7}{|l|}{ (E)strategia municipal (14\%) } \\
\hline \#43 Ejecución del Plan Estratégico & $\frac{\text { Proyectos concluidos exitosamente }}{\text { Proyectos programados }}$ & $12 \%$ & & & & \\
\hline \#44 Divulgación del Plan Estratégico & $\begin{array}{c}\text { Entrevistados que conocen al menos } 25 \% \text { de proyectos de Plan Estratégico } \\
\text { Número total de entrevistados }\end{array}$ & $11 \%$ & & & & \\
\hline $\begin{array}{l}\text { \#45 Participación comunitaria en diseño del Plan } \\
\text { Estratégico }\end{array}$ & $\frac{\text { Proyectos del plan estratégico gestados mediante procesos participativos }}{\text { Número total de proyectos incluidos en Plan Estratégico }}$ & $11 \%$ & & & & \\
\hline \#46 Reportes sobre avance de metas & $\begin{array}{l}\text { Reportes anuales que el alcalde prepara y presenta al Concejo Muni-cipal } \\
\text { sobre el avance de las metas estratégicas }\end{array}$ & $11 \%$ & & & & \\
\hline \#47 Reuniones de verificación de progreso & $\begin{array}{l}\text { Número anual de reuniones que el alcalde realiza con los jefes de de-parta- } \\
\text { mento para dar seguimiento al Plan Estratégico }\end{array}$ & $11 \%$ & & & & \\
\hline \#48 Proyectos estratégicos en salud & $\frac{\text { Proyectos del Plan Estratégico relacionado con el área de Salud }}{\text { Total proyectos incluidos en plan estratégico }}$ & $11 \%$ & & & & \\
\hline \#49 Proyectos estratégicos en agricultura & $\frac{\text { Proyectos del Plan Estratégico relacionado con el área de agricultura }}{\text { Total proyectos incluidos en plan estratégico }}$ & $11 \%$ & & & & \\
\hline \#50 Proyectos estratégicos en seguridad & $\frac{\text { Proyectos del Plan Estratégico relacionado con el área de seguridad }}{\text { Total proyectos incluidos en plan estratégico }}$ & $11 \%$ & & & & \\
\hline \#51 Proyectos estratégicos en educación & $\frac{\text { Proyectos del Plan Estratégico relacionado con el área de educación }}{\text { Total proyectos incluidos en plan estratégico }}$ & $11 \%$ & & & & \\
\hline
\end{tabular}




\begin{tabular}{|c|c|c|c|c|c|c|}
\hline Áreas e indicadores & Razones para cálculo & $\begin{array}{l}\% \\
/ 1\end{array}$ & 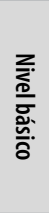 & 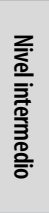 & 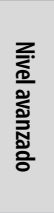 & 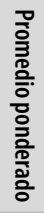 \\
\hline \multicolumn{7}{|l|}{ (R)endición de cuentas y comunicación (15\%) } \\
\hline \#52 Medios impresos de rendición de cuentas & $\frac{\text { Cantidad anual de medios impresos utilizados para comunicación }}{\text { Total de la población del cantón / } 10000}$ & $10 \%$ & & & & \\
\hline $\begin{array}{l}\text { \#53 Informes de rendición de cuentas presentados } \\
\text { al Concejo }\end{array}$ & $\begin{array}{l}\text { Cantidad anual de informes sobre rendición de cuentas presentados y aproba- } \\
\text { dos por el Concejo Municipal }\end{array}$ & $10 \%$ & & & & \\
\hline \#54 Programas de radio y TV & $\frac{\text { Participaciones anuales en radio y TV como estrategia comunicación }}{\text { Total de la población del cantón / } 10000}$ & $10 \%$ & & & & \\
\hline $\begin{array}{l}\text { \#55 Visitas a sección de rendición de cuentas en } \\
\text { página web }\end{array}$ & $\frac{\text { Visitas anuales sección de página web utilizada para rendir cuentas }}{\text { Total anual de visitas a la página web }}$ & $10 \%$ & & & & \\
\hline \#56 Procesos judiciales iniciados contra funcionarios & $\frac{\text { Procesos judiciales iniciados contra funcionarios actos contra interés público }}{\text { Total de funcionarios municipales }}$ & $10 \%$ & & & & \\
\hline \#57 Quejas por cada 10.000 habitantes & $\frac{\text { Quejas anuales presentadas por población relacionadas con ética }}{\text { Total de la población del cantón / } 10000}$ & $10 \%$ & & & & \\
\hline $\begin{array}{l}\text { \#58 Solicitudes de información atendidas oportu- } \\
\text { namente }\end{array}$ & $\frac{\text { Cantidad anual solicitudes de información tramitadas oportunamente }}{\text { Total anual de solicitudes de información }}$ & $10 \%$ & & & & \\
\hline $\begin{array}{l}\text { \#59 Cumplimiento recomendaciones órganos super- } \\
\text { visión nacionales }\end{array}$ & $\frac{\text { Recomendaciones de órganos supervisores nacionales ya implementadas }}{\text { Total Recomendaciones de órganos supervisores nacionales }}$ & $10 \%$ & & & & \\
\hline $\begin{array}{l}\text { \# } 60 \text { Cumplimiento recomendaciones órganos } \\
\text { supervisión internos }\end{array}$ & $\frac{\text { Recomendaciones de órganos supervisores interno ya implementadas }}{\text { Total Recomendaciones de órganos supervisores internos }}$ & $10 \%$ & & & & \\
\hline $\begin{array}{l}\text { \#61 Participación de organizaciones civiles en moni- } \\
\text { toreo político }\end{array}$ & $\frac{\text { Organizaciones civiles que participan en monitoreos de gestión pública }}{\text { Total organizaciones civiles del cantón }}$ & $10 \%$ & & & & \\
\hline \multicolumn{7}{|l|}{ (A)dministración de recursos financieros (14\%) } \\
\hline \#62 Recaudación de ingresos propios & $\begin{array}{l}\frac{\text { Ingresos propios reales }}{\text { Ingresos propios presupuestados }} \\
\text { In }\end{array}$ & $10 \%$ & & & & \\
\hline \#63 Ingresos propios por habitante & $\frac{\text { Ingresos propios reales }}{\text { Población del cantón }}$ & $10 \%$ & & & & \\
\hline \#64 Ingresos propios por funcionario municipal & $\frac{\text { Ingresos propios reales }}{\text { Números de funcionarios municipales }}$ & $10 \%$ & & & & \\
\hline $\begin{array}{l}\text { \#65 Impuesto bienes inmuebles por unidad habi- } \\
\text { tacional }\end{array}$ & $\frac{\text { Ingresos reales recaudados por impuesto de bienes inmuebles }}{\text { Número de unidades habitacionales del cantón }}$ & $10 \%$ & & & & \\
\hline \#66 Ejecución egresos respecto a lo presupuestado & $\begin{array}{c}\text { Egresos ejecutados } \\
\text { Egresos presupuestados }\end{array}$ & $10 \%$ & & & & \\
\hline $\begin{array}{l}\text { \#67 Egresos destinados a prestación de servicios } \\
\text { comunitarios }\end{array}$ & $\frac{\text { Gastos de capital + gasto en prestación de servicios comunitarios }}{\text { Egreso total }}$ & $10 \%$ & & & & \\
\hline \#68 Egresos destinados a la administración municipal & $\frac{\text { Gastos de Administración }}{\text { Egreso total }}$ & $10 \%$ & & & & \\
\hline \#69Total gasto ejecutado por habitante del cantón & $\begin{array}{l}\text { Egreso total } \\
\text { Población del cantón }\end{array}$ & $10 \%$ & & & & \\
\hline $\begin{array}{l}\text { \#70 Gasto ejecutado por habitante en prestación } \\
\text { servicios }\end{array}$ & $\frac{\text { Gastos de capital + gasto en prestación de servicios comunitarios }}{\text { Población del cantón }}$ & $10 \%$ & & & & \\
\hline $\begin{array}{l}\text { \#71 Gasto ejecutado por unidad habitacional en } \\
\text { prestación servicios }\end{array}$ & $\frac{\text { Gastos de capital + gasto en prestación de servicios comunitarios }}{\text { Número de unidades habitacionales del cantón }}$ & $10 \%$ & & & & \\
\hline
\end{tabular}

Fuente: Elaboración propia, 2012. 
Para obtener el promedio ponderado de tipo cuantitativo, se multiplica cada índice por el peso ponderado del elemento para obtener una calificación del elemento. Entonces, se suman las puntuaciones de cada elemento y se dividen entre cinco. Este último cálculo tiene un valor entre 1 y 3 y permite ubicar al gobierno local en uno de cinco niveles de gestión: nivel básico, transición hacia el nivel intermedio, nivel intermedio, transición hacia nivel avanzado y nivel avanzado, según la tabla 4.

\section{TABLA 4 \\ NIVELES DE GESTIÓN SEGÚN LOS INDICADORES CUANTITATIVOS}

\begin{tabular}{|l|c|c|}
\hline \multicolumn{1}{|c|}{ Nivel de gestión } & Nivel inferior & Nivel superior \\
\hline Nivel básico & 1,00 & 1,40 \\
\hline Transición hacia intermedio & 1,41 & 1,80 \\
\hline Nivel intermedio & 1,81 & 2,20 \\
\hline Transición hacia avanzado & 2,21 & 2,60 \\
\hline Nivel avanzado & 2,61 & 3,00 \\
\hline
\end{tabular}

Fuente: Elaboración propia, 2012.

\section{Indicadores cualitativos}

SISTERA reconoce que el cálculo cuantitativo no considera algunas características propias del fenómeno investigado, en especial aquellas relacionadas con la gestión del recurso humano y el servicio al contribuyente. En otras áreas, los indicadores cualitativos proveen información adicional que permite complementar el análisis cuantitativo. Existen 31 indicadores cualitativos para evaluar la gestión municipal en términos cualitativos.

Se utilizan indicadores cualitativos para recolectar información en las siguientes áreas: a) política de servicio al contribuyente, b) política de recursos humanos, c) sistemas de información, d) planificación estratégica, e) transparencia en la función pública y f) control gerencial. En el Anexo 2 se muestran las tablas de valoración para estos indicadores.

El evaluador, pondera los resultados de las categorías anteriores, obteniendo una calificación cuyo valor se ubica entre 1 y 3 , y que corresponde con uno de los siguientes niveles de gestión: nivel básico, transición hacia el nivel intermedio, nivel intermedio, transición hacia nivel avanzado y nivel avanzado, que se asigna según la misma normativa de los indicadores cuantitativos.

\section{Cálculo de los indicadores de gestión cantonales}

Para obtener el indicador cantonal mixto se ponderan los indicadores cuantitativos y cualitativos en las siguientes proporciones: 60\% corresponde a la calificación cuantitativa y $40 \%$ se asigna con base en el análisis cualitativo.

La ponderación anterior está basada en la escala del Modelo Analítico Jerárquico de Thomas Saaty (conocido como AHP, por sus siglas en inglés) y los resultados obtenidos mediante el análisis factorial. Este último permite organizar los indicadores cualitativos y cuantitativos de acuerdo con su influencia sobre la gestión municipal. Luego, mediante el Modelo AHP se organizan las variables en cinco grupos y se le asigna un valor numérico a cada una. Las categorías son las siguientes:

1 = igualmente preferida

3 = moderadamente preferida

5 = fuertemente preferida

7 = muy fuertemente preferida

$9=$ extremadamente preferida 
Posteriormente se utiliza la clasificación anterior, para calcular un promedio ponderado y obtener los pesos de los indicadores cuantitativos y cualitativos, que son del $60 \%$ y $40 \%$, respectivamente. El uso preponderante de indicadores cuantitativos es congruente con otros modelos que también están basados en investigaciones mixtas y tiene las siguientes ventajas: facilita la comparación de los niveles de gestión entre los cantones, permite repetir el cálculo del indicador de gestión con mayor facilidad y facilita la recolección de los datos.

La calificación global por cantón es un valor entre 1 y 3 , que se utiliza para ubicar el nivel de gestión del gobierno local en una de las siguientes opciones: nivel básico, transición hacia el nivel intermedio, nivel intermedio, transición hacia nivel avanzado y nivel avanzado. La escala para estos niveles de gestión es la misma ya descrita para los indicadores cuantitativos.

\section{Cálculo del indicador de gestión provincial}

Para facilitar la comparación de los niveles de gestión, a nivel provincial, se calcula un indicador compuesto que incluye las evaluaciones de todos los cantones de la provincia de Puntarenas. Esta evaluación global es un promedio ponderado de los resultados de cada ayuntamiento.

Se usa la población de cada cantón como variable de ponderación. Este valor permite ponderar el indicador provincial con base en un criterio que es homogéneo en todos los municipios. De esta manera, el peso de una municipalidad, en términos del indicador provincial, es igual a la población relativa del cantón, aún y cuando existan diversas diferencias en términos del tamaño de los presupuestos municipales y las características de la población.

Con base en los mismos límites establecidos para los indicadores cuantitativos se calcula el indicador provincial, que también toma valores ubicados entre 1 y 3 . Mediante una tabla cualitativa se ubica este valor en uno de cinco niveles de gestión: básico, transición hacia intermedio, intermedio, transición hacia avanzado y avanzado.

\section{CONCLUSIONES}

Las conclusiones finales de este trabajo están divididas en dos grupos. Primero se presentan aquellas relacionadas con los ejes estratégicos de la gestión municipal en Puntarenas. Después se ofrecen algunas generalizaciones razonables a nivel país.

\section{Sobre los ejes estratégicos de la gestión municipal}

La influencia del modelo puntarenense de gestión municipal sobre el desarrollo de la provincia se mide utilizando seis ejes estratégicos. A continuación se presentan las principales conclusiones sobre cada uno.

- Liderazgo y planificación estratégica: aunque existen planes estratégicos a nivel de todas las municipalidades puntarenenses, no existe un proceso articulado y eficiente, que permita, mediante un grupo de indicadores, medir el avance de los proyectos que se consideran prioritarios de desarrollo de la provincia. Al analizar las áreas de educación, agricultura, salud y seguridad se evidencia que la mayoría de los proyectos no tienen visión de largo plazo y se limitan a coordinar esfuerzos específicos con algunas instituciones, tales como el Ministerio de Salud y el Ministerio de Seguridad Pública. La mayoría de las acciones, se enfocan en problemas puntuales y no están diseñadas para promover el desarrollo económico de la provincia en el largo plazo. 
- Compromiso con el desarrollo de las personas: la educación universal y de calidad es fundamental para promover el desarrollo de una región. El modelo de gestión municipal en Puntarenas tiene pocas alternativas educativas para la comunidad y los funcionarios municipales. Las opciones de capacitación que se ofrecen a los empleados del ayuntamiento, se circunscriben a cursos gratuitos de algunas instituciones como el IFAM y el Ministerio de Economía, Industria y Comercio. Estas alternativas de capacitación se eligen con base en la oferta disponible, y no de acuerdo con las necesidades de entrenamiento de los funcionarios municipales, ya que, los ayuntamientos no realizan diagnósticos en este particular. En relación con las oportunidades educativas para las comunidades, se determinó que estas son escasas y su oferta no guarda relación con el plan estratégico de desarrollo. En la mayoría de los casos, los ayuntamientos, no tienen convenios con otras organizaciones públicas y privadas, para promover una oferta educativa que concuerde con las necesidades especificas de los funcionarios municipales y las comunidades. Esta situación dificulta el fomento de competencias y capacidades, en el recurso humano, que se consideran claves para el desarrollo del cantón.

- Uso de recursos financieros y materiales: aunque el uso adecuado de los recursos disponibles promueve la eficiencia de gestión, existen condiciones en la provincia de Puntarenas que representan un riesgo para lograr este objetivo. Aunque los gobiernos locales siguen la normativa legal aplicable (tal como la Ley de Contratación Administrativa y la Ley de Control Interno), no existen órganos independientes que atiendan las denuncias de los ciudadanos. Sólo la Municipalidad de Osa tiene Contraloría de Servicios y en algunos ayuntamientos (como Parrita) la función de auditoría es desempeñada por el Departamento de Contabilidad.

- Relación con los usuarios de servicios: ninguna municipalidad tiene un procedimiento regular y eficiente para medir la satisfacción de los usuarios de servicios. La dificultad para medir o identificar áreas de oportunidad, mediante encuestas de satisfacción, es una limitante para tomar acciones orientadas a mejorar la eficiencia de la gestión municipal.

- Prestación de servicios: los servicios públicos que prestan las municipalidades influyen sobre la calidad de vida de la comunidad y, por lo tanto, en el desarrollo de la región. En este sentido es de importancia destacar que, con excepción de la construcción y reparación de las vías públicas, no existe un sistema de acreditación de calidad de los servicios municipales que se utilice en forma consistente en la provincia de Puntarenas. Aunque existen algunas excepciones (como la Municipalidad de Montes de Oro que tiene un sistema de acreditación de la calidad del agua), estas se limitan a situaciones específicas y no abarcan la totalidad de servicios que ofrecen los ayuntamientos. Esta situación impide que los gobiernos locales tengan información confiable para identificar áreas de oportunidad en el ofrecimiento de los servicios públicos.

- Información y comunicación: aunque toda la información está disponible, debido a la naturaleza pública de los gobiernos locales, no existe un proceso proactivo de comunicación hacia la comunidad. La rendición de cuentas se limita, en la mayoría de los casos, a las opciones que por imperativo legal se deben utilizar, tales como las sesiones del Concejo Municipal. El uso de redes sociales, páginas web actualizadas e informativas, correo electrónico, y otros más tradiciona- 
les, como volantes, panfletos y reuniones comunales es limitado, con pocas excepciones que ocurren en las Municipalidades de Montes de Oro y Parrita.

\section{Generalizaciones a nivel país}

Con base en la investigación realizada, es posible deducir las siguientes generalizaciones a nivel país:

- En relación con la planeación estratégica, no hay un seguimiento efectivo del plan estratégico ni se da seguimiento regular al mismo para implementar un plan de acciones correctivas que permita atender de manera oportuna cualquier debilidad que se identifique.

- Con respecto al uso de las tecnologías de información, las municipalidades no hacen uso eficiente ni generalizado de las oportunidades que ofrece la tecnología para usarla una alternativa para mejorar sus procesos de gestión y la comunicación con la comunidad.

- Sobre las normas de calidad, los ayuntamientos no utilizan sistemas reconocidos a nivel nacional o internacional, para certificar la calidad de los sistemas de gestión, de forma tal que puedan medir, en forma fidedigna, el porcentaje de cumplimiento de las especificaciones técnicas que tienen los servicios que ofrecen a las comunidades.

- Las municipalidades tienen una estrategia de recursos humanos que no favorece la eficiencia de la gestión municipal. No se efectúan en forma regular (al menos una vez al año) evaluaciones del desempeño de los funcionarios municipales, ni se tienen planes de capacitación acorde con las necesidades identificadas.
- En relación con el control interno, los mecanismos de participación ciudadana no favorecen el involucramiento proactivo e independiente de la sociedad civil en la presentación de denuncias y sugerencias para mejorar la gestión municipal.

- Los ayuntamientos no utilizan, de manera proactiva y constante, las opciones disponibles para favorecer la comunicación con la comunidad y como medio para rendir cuentas y mejorar la transparencia de la gestión pública. El uso de redes sociales, páginas web, correo electrónico, volantes y reuniones comunales es limitado.

\section{RECOMENDACIONES}

El Modelo SISTERA de gestión municipal constituye un instrumento para permitir a los gobiernos locales mejorar la eficiencia de su labor y, de esta manera, promover el desarrollo local de sus respectivos cantones. Las siguientes recomendaciones ayudan a potenciar los efectos positivos de la aplicación de este modelo:

1. Promover la participación comunal. Es necesario crear conciencia en la población sobre la importancia de participar, activamente, en las actividades de la municipalidad como medio de control político y como mecanismo para promover el desarrollo local. Es importante que la comunidad entienda cómo la gestión municipal afecta su bienestar y fomentar un compromiso compartido de gestión entre ésta y la municipalidad, de forma tal que los habitantes del cantón tomen parte activa en las actividades del gobierno local. La experiencia de la Municipalidad de Parrita es valiosa y consiste en realizar reuniones regulares con la población como medio de interacción entre la municipalidad y los ciudadanos. Estas reuniones ocurren en el parque público y se realizan actividades culturales y recreativas para atraer las 
personas. Asimismo, se realizan actividades similares en las cabeceras de distrito. Esta buena práctica de gestión municipal puede ser imitada por otros gobiernos locales.

2. Mejorar el uso de la tecnología como herramienta de gestión municipal. Las municipalidades puntarenenses hacen uso limitado de los recursos tecnológicos como herramienta de gestión. Algunas municipalidades tienen página web, pero no se encuentra actualizada o no se utiliza eficientemente como medio de comunicación con la comunidad. La Municipalidad de Esparza y la Municipalidad de Garabito son ejemplos positivos de cómo utilizar las tecnologías de la información como medio de comunicación y rendición de cuentas. Estos gobiernos locales actualizan sus páginas web en forma regulary ofrecen información de importancia para la comunidad, entre estos: requisitos para trámites municipales, rendición de cuentas, foros y formularios de contacto, noticias y anuncios, preguntas frecuentes, información geográfica y turística del cantón. En el caso de la Municipalidad de Garabito, incluso, se ofrece el pago de algunos servicios en línea. La posibilidad de pagar servicios en línea es valorada por los contribuyentes y contribuye a disminuir el nivel de morosidad. Internamente, también, es posible utilizar la tecnología para mejorar el nivel de servicio al contribuyente, esto se logra mediante eficientes sistemas de información basados en computadora, acceso a portales municipales que estén actualizados y con información relevante, comunicación con la comunidad mediante medios electrónicos y un uso eficiente de las redes sociales.

3. Mejorar la calidad de los servicios que se ofrecen a la comunidad. Dada la relación que existe entre la calidad de los servicios que se ofrecen a la comunidad y el nivel de satisfacción de los ciudadanos sobre la gestión que realiza la municipalidad, es necesario, destacar la necesidad de mejorar la calidad de los servicios municipales, mediante sistemas de acreditación. Existen algunos esfuerzos aislados, en este sentido. Sin embargo, en general, la calidad de los servicios municipales no está acreditada en la provincia de Puntarenas. Un caso especial, es la Municipalidad de Montes de Oro que es el único gobierno local que administra directamente el suministro de agua potable. Este municipio tiene un acuerdo con el Instituto Costarricense de Acueductos y Alcantarillados (ICAA) para la evaluación y acreditación regular de la calidad del agua. La municipalidad oromontana obtuvo una calificación alta en el nivel de satisfacción comunal por la calidad del servicio de agua potable. Es necesario que las municipalidades continúen trabajando con el objetivo de certificar los servicios municipales que ofrecen. Se debe evaluar la creación de un Sistema Nacional de Acreditación de los Servicios Municipales (como el caso chileno), o hacer uso de alguno de los sistemas de acreditación que son comunes en el mercado, tales como: las Normas ISO o la normativa de las Naciones Unidas sobre Carbono Neutral. Otro aspecto de importancia sobre el tema de la calidad de los servicios municipales es la necesidad de crear Oficinas de Información y Contralorías de Servicio, mismas que, por mandato de la Contraloría General de la República, deben promover la calidad de los servicios municipales y servir de foro para recepción de denuncias por mala prestación de servicios.

4. Promover programas formales de capacitación para los funcionarios municipales. Los funcionarios municipales adecuadamente capacitados están en una mejor posición para atender mejor sus responsabilidades. Por lo tanto, es fundamental que los gobiernos locales se preocupen en forma activa 
por mejorar las habilidades de sus colaboradores. El Instituto de Fomento y Asesoría Municipal (IFAM) tiene programas de formación municipal en áreas como: modernización municipal, cooperación internacional, administración tributaria, ética, planificación regional y gestión del cobro. Existen otras opciones de capacitación con instituciones como el Instituto Nacional de Aprendizaje, que ofrece cursos en el área de idiomas, administración de negocios y computación, o mediante las universidades públicas. Específicamente la Universidad de Costa Rica ofrece el programa de Maestría en Administración y Derecho Municipal y la Universidad Estatal a Distancia tiene el Instituto de Formación y Capacitación Municipal. Es necesario que los gobiernos locales realicen un esfuerzo proactivo para encontrar opciones de formación para sus funcionarios. El financiamiento de estas alternativas educativas puede hacerse mediante recursos municipales o mediante el aprovechamiento efectivo de otras alternativas disponibles.

5. Planificar y gestionar políticas específicas en agricultura, salud, educación y seguridad. Existen pocas políticas específicas en estos sectores prioritarios para el desarrollo. En el área de seguridad, algunas municipalidades tienen programas de Policía Municipal, entre ellas la Municipalidad de Aguirre y la Municipalidad de Garabito. En el área de agricultura y salud, no existen políticas formales para desarrollar estos sectores. Mientras tanto, el área de educación muestra un desarrollo incipiente en las municipalidades puntarenenses. Algunas municipalidades ofrecen cursos a la comunidad, pero no tienen un programa formal para tal efecto. Es necesario que, los gobiernos locales enfoquen su atención en estos sectores para el beneficio de la comunidad.
6. Fortalecer los programas sociales que contribuyen a disminuir la brecha social y aumentar la cohesión social en el cantón. Las municipalidades deben fortalecer las políticas orientadas a la protección de los sectores más vulnerables: niños, jóvenes, personas de la tercera edad y mujeres. Esto significa tomar acciones concretas para solicitar la colaboración de instituciones públicas y privadas (tales como el Instituto Mixto de Ayuda Social, Fondo de Desarrollo de Asignaciones Familiares, Instituto Nacional de las Mujeres, Junta de Protección Social y otras organizaciones no gubernamentales) para implementar programas destinados a mejorar la educación y mejorar el acceso al alimento, la salud, el empleo y los servicios básicos en estos grupos menos favorecidos. También involucra una coordinación más estrecha entre los gobiernos locales y otras instituciones de corte social, para mejorar, en conjunto, la distribución de ayudas disponibles para los grupos menos favorecidos, siempre con fundamento en criterios técnicos y con adecuada supervisión para evitar abusos en el ejercicio del poder político.

7. Fortalecer el uso eficiente de los recursos financieros municipales. Los municipios deben mejorar la planificación financiera para ejecutar (con la participación y control de los ciudadanos) sus presupuestos con un fuerte contenido social y enfocados en la creación de infraestructura cantonal, que promuevan la democracia económica y se orienten a la erradicación de la corrupción en la función pública. El gasto administrativo y político debe ser el mínimo posible, para dedicar esos recursos al desarrollo de la comunidad y el fortalecimiento de la gobernabilidad cantonal. Eso implica mejorar los sistemas de cobro y aumentar la eficiencia en la recolección de los recursos propios, sin olvidarse de establecer los mecanismos de control interno apropiados que aseguren el uso transparente de los recursos públicos. 


\section{REFERENCIAS}

Aguilar, Justo. (2009) Los desafíos de la municipalidad en el siglo XXI. Obtenido el 1 de marzo de 2012 desde http:// www.ifam.go.cr/PaginalFAM/ifams/Descargas/CDI/capacitaciones/LOS\%20DESAFIOS\%20DE\%20LA\%20MUNICIPALIDAD\%20EN\%20EL\%20SIGLO\%20XXI.pdf

Araujo, Adolfo (2009). El Macroentorno (Entorno General). Obtenido el 8 de enero de 2012 desde http://inf-tek. blogia.com/2009/020302-1.2-el-macroentorno-entorno-general-.php

Asencio Romero, Pedro. (2006). El libro de la gestión municipal. Ediciones Días de Santos. Buenos Aires, Argentina.

Contraloría General de la República. (2009). Análisis y Opinión sobre la Gestión de los Gobiernos Locales en el periodo 2008. San José, Costa Rica : División de Fiscalización Operativa y Evaluativa. Área de Servicios Municipales. Cuarto Informe. DFOE-SM-7-2009

Escorsa Pere Castells, Valls Pasola, Jaume. (2003). Tecnología e innovación en la empresa. Universidad Politécnica de Cataluña. Ediciones UPC : Barcelona, España.
Hinojosa, Antonio. (2006). Innovación de proceso. Cuadernos de Gestión Tecnológica. Secretaría de Economía: México D.F., México.

Instituto Chileno de Estudios Municipales (2009). Buenas prácticas de gestión municipal: resumen de iniciativas nacionales e internacionales. Obtenido el 22 de setiembre de 2009 desde http://www.ichem.cl/archivo/ TRA_20.pdf

Instituto Nacional de Estadísticas y Censos (2011). Población total proyectada por sexo. Obtenido el 10 de febrero de 2013 desde http://www.inec.go.cr/Web/ Home/GeneradorPagina.aspx.

Moreno, Miguel. (2001). La reorganización territorial del ayuntamiento rural. Un enfoque alternativo para la modernización de los municipios rurales del país en los umbrales del siglo XXI. Plaza Valdés S.A. de C.V. : México D.F., México.

Pérez, Artemio. (2007). Políticas públicas para la promoción del desarrollo económico territorial. Una aproximación desde la práctica. Agencia Suiza para el Desarrollo y la Cooperación : Quito, Ecuador.

Recibido: 3 de julio de 2012 Aceptado: 29 julio de 2012

\section{Anexo 1 \\ Niveles de gestión para indicadores cuantitativos}

\section{A. Servicios municipales}

TABLA 5

NIVEL DE LOS INDICADORES CUANTITATIVOS SOBRE SERVICIOS MUNICIPALES

\begin{tabular}{|c|c|c|c|}
\hline Indicador & Nivel básico & Nivel intermedio & Nivel avanzado \\
\hline $\begin{array}{l}\text { Porcentaje de inversión en programas de aseguramiento de la } \\
\text { calidad }\end{array}$ & Menor a un 5\% & $\begin{array}{l}\text { Mayor o igual que un } 5 \% \\
\text { pero menos que un } 8 \%\end{array}$ & Mayor o igual que un 8\% \\
\hline $\begin{array}{l}\text { Porcentaje de inversión en el desarrollo de aplicaciones de venta- } \\
\text { nilla (páginas web, correo electrónico, catálogos digitales, etc.) }\end{array}$ & Menor a un 5\% & $\begin{array}{l}\text { Mayor o igual que un } 5 \% \\
\text { pero menos que un } 8 \%\end{array}$ & Mayor o igual que un 8\% \\
\hline Nivel de satisfacción del contribuyente & Menor que 70\% & $\begin{array}{l}\text { Mayor } 0 \text { igual que un } 70 \% \\
\text { pero menor que } 90 \%\end{array}$ & Mayor o igual que un $90 \%$ \\
\hline $\begin{array}{l}\text { Tiempo de respuesta en atención de quejas, peticiones y } \\
\text { reclamos }\end{array}$ & $\begin{array}{l}\text { Mayor o igual de } 336 \\
\text { horas }\end{array}$ & $\begin{array}{l}\text { Mayor } 0 \text { igual que } 48 \text { horas } \\
\text { pero menor de } 336 \text { horas }\end{array}$ & Menor 0 igual que 48 horas \\
\hline Exactitud del cobro de los servicios & Menor que $80 \%$ & $\begin{array}{l}\text { Mayor o igual que un } 80 \% \\
\text { pero menor que } 95 \%\end{array}$ & Mayor o igual que un 95\% \\
\hline Disponibilidad de los servicios municipales & Menor que el $80 \%$ & $\begin{array}{l}\text { Mayor o igual que un } 80 \% \\
\text { pero menor que } 95 \%\end{array}$ & Mayor o igual que un $95 \%$ \\
\hline
\end{tabular}




\begin{tabular}{|l|l|l|l|}
\hline Tiempo de espera para ser atendido & $\begin{array}{l}\text { Mayor o igual de 30 } \\
\text { minutos }\end{array}$ & $\begin{array}{l}\text { Mayor 15 minutos pero } \\
\text { menor de 30 minutos }\end{array}$ & $\begin{array}{l}\text { Menor o igual que 15 } \\
\text { minutos }\end{array}$ \\
\hline $\begin{array}{l}\text { Porcentaje de gasto en ayudas sociales a los grupos socialmente } \\
\text { vulnerables }\end{array}$ & Menor a un 10\% & $\begin{array}{l}\text { Mayor o igual que un 10\% } \\
\text { pero menos que un 15\% }\end{array}$ & Mayor o igual que un 15\% \\
\hline Porcentaje de gasto en limpieza y ornato del cantón & Menor a un 5\% & $\begin{array}{l}\text { Mayor o igual que un 5\% } \\
\text { pero menos que un 8\% }\end{array}$ & Mayor 0 igual que un 8\% \\
\hline Porcentaje de gasto en servicios de seguridad ciudadana & Menor a un 10\% & $\begin{array}{l}\text { Mayor o igual que un 10\% } \\
\text { pero menos que un 15\% }\end{array}$ & Mayor o igual que un 15\% \\
\hline $\begin{array}{l}\text { Porcentaje de la población cubierta por el servicio de recolec- } \\
\text { ción de desechos sólidos }\end{array}$ & Menor que 80\% & $\begin{array}{l}\text { Mayor o igual que un 80\% } \\
\text { pero menor que 95\% }\end{array}$ & Mayor o igual que un 95\% \\
\hline
\end{tabular}

Fuente: Elaboración propia, 2012.

\section{B. Innovación organizacional}

TABLA 6

NIVEL DE LOS INDICADORES CUANTITATIVOS SOBRE INNOVACIÓN ORGANIZACIONAL

\begin{tabular}{|c|c|c|c|}
\hline Indicador & Nivel básico & Nivel intermedio & Nivel avanzado \\
\hline $\begin{array}{l}\text { Horas anuales por funcionario dedicadas a trabajar en } \\
\text { actividades de innovación }\end{array}$ & Menos de 190 horas & $\begin{array}{l}\text { Mayor o igual que } 190 \\
\text { horas pero menos de } 240 \\
\text { horas }\end{array}$ & Mayor o igual que 240 horas \\
\hline $\begin{array}{l}\text { Porcentaje de inversión en bienes de capital que impliquen } \\
\text { un cambio tecnológico }\end{array}$ & Menos del 10\% & $\begin{array}{l}\text { Mayor o igual que el } 10 \% \\
\text { pero menos del } 15 \%\end{array}$ & Mayor 0 igual que el 15\% \\
\hline $\begin{array}{l}\text { Porcentaje de inversión en actividades de modernización } \\
\text { organizacional }\end{array}$ & Menos del $5 \%$ & $\begin{array}{l}\text { Mayor o igual que el } 5 \% \\
\text { pero menos de } 10 \%\end{array}$ & Mayor o igual que el 10\% \\
\hline $\begin{array}{l}\text { Porcentaje de inversión en programas de modernización } \\
\text { de procesos }\end{array}$ & Menos del $5 \%$ & $\begin{array}{l}\text { Mayor o igual que el } 5 \% \\
\text { pero menos de } 10 \%\end{array}$ & Mayor o igual que el 10\% \\
\hline $\begin{array}{l}\text { Vínculos con organizaciones que promueven mejoras de } \\
\text { innovación }\end{array}$ & Menor o igual a 2 alianzas & $\begin{array}{l}\text { Más de dos alianzas pero } \\
\text { menor o igual que } 4 \\
\text { alianzas }\end{array}$ & Más de 4 alianzas \\
\hline $\begin{array}{l}\text { Porcentaje de iniciativas presentadas a la municipalidad } \\
\text { que impliquen innovación en procesos y organización }\end{array}$ & Menos del 10\% & $\begin{array}{l}\text { Mayor o igual que el } 10 \% \\
\text { pero menos del } 20 \%\end{array}$ & Mayor o igual que el 30\% \\
\hline $\begin{array}{l}\text { Porcentaje de iniciativas aprobadas e implementadas que } \\
\text { impliquen innovación en procesos y organización }\end{array}$ & Menos del $60 \%$ & $\begin{array}{l}\text { Mayor o igual que el } 60 \% \\
\text { pero menos del } 85 \%\end{array}$ & Mayor o igual que el $85 \%$ \\
\hline $\begin{array}{l}\text { Número de proyectos activos sobre innovación organiza- } \\
\text { cional y de procesos }\end{array}$ & Menor 0 igual que 3 & $\begin{array}{l}\text { Mayor que } 3 \text { pero menor } 0 \\
\text { igual que } 5\end{array}$ & Mayor 0 igual que 6 \\
\hline $\begin{array}{l}\text { Número de funcionarios municipales matriculados en } \\
\text { cursos de capacitación sobre in-novación }\end{array}$ & Menor del 15\% & $\begin{array}{l}\text { Mayor o igual que } 15 \% \\
\text { pero menor que } 25 \%\end{array}$ & Mayor o igual que 25\% \\
\hline
\end{tabular}

Fuente: Elaboración propia, 2012. 


\section{Capacitación municipal y comunal}

TABLA 7

\section{NIVEL DE LOS INDICADORES CUANTITATIVOS SOBRE CAPACITACIÓN MUNICIPAL Y COMUNAL}

\begin{tabular}{|c|c|c|c|}
\hline Indicador & Nivel básico & Nivel intermedio & Nivel avanzado \\
\hline $\begin{array}{l}\text { Cantidad anual de horas de capacitación por funcionario muni- } \\
\text { cipal (no incluyendo la capacitación en innovación) }\end{array}$ & Menor 0 igual de 32 horas & $\begin{array}{l}\text { Mayor de } 32 \text { horas pero } \\
\text { menor o igual que } 48 \text { horas }\end{array}$ & Mayor que 48 horas \\
\hline $\begin{array}{l}\text { Cantidad anual de horas de capacitación por cada } 10.000 \\
\text { habitantes del cantón }\end{array}$ & $\begin{array}{l}\text { Menor } 0 \text { igual que } 800 \\
\text { horas }\end{array}$ & $\begin{array}{l}\text { Mayor que } 800 \text { horas pero } \\
\text { menor o igual a } 1200 \text { horas }\end{array}$ & Mayor que 1200 horas \\
\hline $\begin{array}{l}\text { Alianzas con instituciones educativas que ofrecen opciones de } \\
\text { capacitación municipal y comunal }\end{array}$ & Menor 0 igual que 2 & $\begin{array}{l}\text { Mayor que } 2 \text { pero menor } 0 \\
\text { igual que } 4\end{array}$ & Mayor que 4 \\
\hline $\begin{array}{l}\text { Porcentaje del presupuesto total dedicado a la capacitación de } \\
\text { los funcionarios municipales }\end{array}$ & Menor o igual que un 3\% & $\begin{array}{l}\text { Mayor que un } 3 \% \text { pero } \\
\text { menor } 0 \text { igual que } 5 \%\end{array}$ & Mayor que un $5 \%$ \\
\hline $\begin{array}{l}\text { Porcentaje del presupuesto total dedicado a la capacitación de } \\
\text { la comunidad }\end{array}$ & Menor o igual que un 3\% & $\begin{array}{l}\text { Mayor que un } 3 \% \text { pero } \\
\text { menor } 0 \text { igual que } 5 \%\end{array}$ & Mayor que un $5 \%$ \\
\hline $\begin{array}{l}\text { Nivel de satisfacción del funcionario municipal por la capacita- } \\
\text { ción recibida }\end{array}$ & Menor o igual que un 80\% & $\begin{array}{l}\text { Mayor que } 80 \% \text { pero menor } \\
\text { o igual que } 90 \%\end{array}$ & Mayor que 90\% \\
\hline $\begin{array}{l}\text { Nivel de satisfacción de la comunidad por la capacitación } \\
\text { recibida }\end{array}$ & Menor o igual que un 80\% & $\begin{array}{l}\text { Mayor que } 80 \% \text { pero menor } \\
\text { o igual que } 90 \%\end{array}$ & Mayor que 90\% \\
\hline $\begin{array}{l}\text { Número de cursos abiertos y cerrados (con una duración míni- } \\
\text { ma de } 8 \text { horas) por cada } 10.000 \text { habitantes. }\end{array}$ & Menor o igual que 100 & $\begin{array}{l}\text { Mayor que } 100 \text { pero menor } \\
\text { o igual que } 150\end{array}$ & Mayor que 150 \\
\hline $\begin{array}{l}\text { Porcentaje de funcionarios municipales con grado mínimo de } \\
\text { bachiller universitario }\end{array}$ & Menor 0 igual que un 50\% & $\begin{array}{l}\text { Mayor que un } 50 \% \text { pero } \\
\text { menor o igual que un } 80 \%\end{array}$ & Mayor que un 80\% \\
\hline $\begin{array}{l}\text { Porcentaje de funcionarios municipales con grado mínimo de } \\
\text { licenciado o máster. }\end{array}$ & Menor o igual que un 30\% & $\begin{array}{l}\text { Mayor que un } 30 \% \text { pero } \\
\text { menor o igual que un } 50 \%\end{array}$ & Mayor que un 50\% \\
\hline $\begin{array}{l}\text { Porcentaje de funcionarios que reciben becas o ayudas para el } \\
\text { estudio }\end{array}$ & Menor o igual que un 10\% & $\begin{array}{l}\text { Mayor que } 10 \% \text { pero menor } \\
\text { o igual que } 15 \%\end{array}$ & Mayor que un 15\% \\
\hline $\begin{array}{l}\text { Número de personas que reciben becas } 0 \text { ayudas para el estudio } \\
\text { por cada } 10.000 \text { habitantes. }\end{array}$ & Menor 0 igual de 50 & $\begin{array}{l}\text { Mayor que } 50 \text { pero menor } 0 \\
\text { igual que } 100\end{array}$ & Mayor que 100 \\
\hline
\end{tabular}

Fuente: Elaboración propia, 2012. 


\section{Tecnología de apoyo a la gestión}

TABLA 8

\section{NIVEL DE LOS INDICADORES CUANTITATIVOS SOBRE TECNOLOGÍA DE APOYO A LA GESTIÓN}

\begin{tabular}{|c|c|c|c|}
\hline Indicador & Nivel básico & Nivel intermedio & Nivel avanzado \\
\hline $\begin{array}{l}\text { Porcentaje de cumplimiento de los programas de manteni- } \\
\text { miento de equipos }\end{array}$ & Menor o igual que el $85 \%$ & $\begin{array}{l}\text { Mayor que el } 85 \% \text { pero } \\
\text { menor o igual } 95 \%\end{array}$ & Mayor que 95\% \\
\hline Porcentaje de inversión en tecnología (hardware y software) & Menor 0 igual que $10 \%$ & $\begin{array}{l}\text { Mayor que } 10 \% \text { pero menor } \\
\text { o igual que } 15 \%\end{array}$ & Mayor que 15\% \\
\hline Computadoras por funcionario municipal & Menor 0 igual que 0.7 & $\begin{array}{l}\text { Mayor que } 0.7 \text { pero menor } \\
\text { que } 1\end{array}$ & Mayor 0 igual que 1 \\
\hline $\begin{array}{l}\text { Porcentaje de funcionarios con acceso a correo electrónico e } \\
\text { Internet }\end{array}$ & Menor 0 igual que $70 \%$ & $\begin{array}{l}\text { Mayor que } 70 \% \text { pero menor } \\
\text { que } 100 \%\end{array}$ & Mayor o igual que $100 \%$ \\
\hline $\begin{array}{l}\text { Porcentaje de trámites que los contribuyentes realizan vía } \\
\text { página web }\end{array}$ & Menor que un 10\% & $\begin{array}{l}\text { Mayor o igual que un } 10 \% \\
\text { pero menor que } 15 \%\end{array}$ & Mayor o igual que 15\% \\
\hline Porcentaje de trámites que están disponibles en línea & Menor que un $40 \%$ & $\begin{array}{l}\text { Mayor o igual que un } 40 \% \\
\text { pero menor que } 60 \%\end{array}$ & Mayor que un $60 \%$ \\
\hline $\begin{array}{l}\text { Cantidad de procesos municipales internos que se encuentran } \\
\text { soportados por las tecnologías de la información y comunicación }\end{array}$ & Menor 0 igual que un 70\% & $\begin{array}{l}\text { Mayor que un } 70 \% \text { pero } \\
\text { menor que un } 90 \%\end{array}$ & Mayor o igual que un $90 \%$ \\
\hline $\begin{array}{l}\text { Cantidad de centros inteligentes comunitarios por cada } 10.000 \\
\text { habitantes }\end{array}$ & Menor 0 igual que 2 & $\begin{array}{l}\text { Mayor que } 2 \text { pero menor } 0 \\
\text { igual que } 4\end{array}$ & Mayor que 4 \\
\hline $\begin{array}{l}\text { Porcentaje de los funcionarios municipales que tienen un } \\
\text { alfabetismo tecnológico satisfactorio }\end{array}$ & Menor 0 igual que $70 \%$ & $\begin{array}{l}\text { Mayor que } 70 \% \text { pero menor } \\
\text { que } 100 \%\end{array}$ & Mayor o igual que $100 \%$ \\
\hline $\begin{array}{l}\text { Funcionarios municipales que trabajan directamente en el } \\
\text { Departamento de TICs por cada } 50 \text { computadoras }\end{array}$ & Menor 0 igual que 0.5 & $\begin{array}{l}\text { Mayor que } 0.5 \text { pero menor } \\
\text { que } 1\end{array}$ & Mayor 0 igual que 1 \\
\hline
\end{tabular}

Fuente: Elaboración propia, 2012. 


\section{E. Estrategia municipal}

TABLA 9

NIVEL DE LOS INDICADORES CUANTITATIVOS SOBRE ESTRATEGIA MUNICIPAL

\begin{tabular}{|c|c|c|c|}
\hline Indicador & Nivel básico & Nivel intermedio & Nivel avanzado \\
\hline Porcentaje ejecutado del plan estratégico & Menor 0 igual que un $80 \%$ & $\begin{array}{l}\text { Mayor que un } 80 \% \text { pero } \\
\text { menor que un } 100 \%\end{array}$ & $\begin{array}{l}\text { Mayor } 0 \text { igual que un } \\
100 \%\end{array}$ \\
\hline Divulgación del Plan Estratégico & Menor 0 igual que un $80 \%$ & $\begin{array}{l}\text { Mayor que un } 80 \% \text { pero } \\
\text { menor que un } 100 \%\end{array}$ & $\begin{array}{l}\text { Mayor } 0 \text { igual que un } \\
100 \%\end{array}$ \\
\hline Participación comunitaria en el diseño del plan estratégico & Menor o igual que un 30\% & $\begin{array}{l}\text { Mayor que un } 30 \% \text { pero } \\
\text { menor o igual que un } 50 \%\end{array}$ & $\begin{array}{l}\text { Mayor o igual que un } \\
50 \%\end{array}$ \\
\hline $\begin{array}{l}\text { Cantidad anual de reportes preparados sobre el avance de } \\
\text { metas estratégicas }\end{array}$ & Menor 0 igual que 12 & $\begin{array}{l}\text { Mayor que } 12 \text { pero menor } 0 \\
\text { igual que } 18\end{array}$ & Mayor que 18 \\
\hline $\begin{array}{l}\text { Reuniones realizadas para verificar avance de Plan Estra- } \\
\text { tégico }\end{array}$ & Menor 0 igual que 12 & $\begin{array}{l}\text { Mayor que } 12 \text { pero menor } 0 \\
\text { igual que } 18\end{array}$ & Mayor que 18 \\
\hline $\begin{array}{l}\text { Porcentaje de proyectos estratégicos relacionados con el } \\
\text { área de salud }\end{array}$ & Menor que 10\% & $\begin{array}{l}\text { Mayor o igual que } 10 \% \\
\text { pero menor que } 15 \%\end{array}$ & Mayor o igual que $15 \%$ \\
\hline $\begin{array}{l}\text { Porcentaje de proyectos estratégicos relacionados con la } \\
\text { agricultura }\end{array}$ & Menor que 10\% & $\begin{array}{l}\text { Mayor o igual que } 10 \% \\
\text { pero menor que } 15 \%\end{array}$ & Mayor o igual que $15 \%$ \\
\hline $\begin{array}{l}\text { Porcentaje de proyectos estratégicos relacionados con la } \\
\text { seguridad ciudadana }\end{array}$ & Menor que $10 \%$ & $\begin{array}{l}\text { Mayor o igual que } 10 \% \\
\text { pero menor que } 15 \%\end{array}$ & Mayor o igual que $15 \%$ \\
\hline $\begin{array}{l}\text { Porcentaje de proyectos estratégicos relacionados con la } \\
\text { educación }\end{array}$ & Menor que $10 \%$ & $\begin{array}{l}\text { Mayor o igual que } 10 \% \\
\text { pero menor que } 15 \%\end{array}$ & Mayor o igual que $15 \%$ \\
\hline
\end{tabular}

Fuente: Elaboración propia, 2012. 


\section{F. Rendición de cuentas y comunicación}

TABLA 10

\section{NIVEL DE LOS INDICADORES CUANTITATIVOS SOBRE RENDICIÓN DE CUENTAS Y COMUNICACIÓN}

\begin{tabular}{|c|c|c|c|}
\hline Indicador & Nivel básico & Nivel intermedio & Nivel avanzado \\
\hline $\begin{array}{l}\text { Número de medios impresos utilizados como medio de comu- } \\
\text { nicación y rendición de cuentas por cada } 10.000 \text { habitantes }\end{array}$ & Menor o igual que 12 & $\begin{array}{l}\text { Mayor que } 12 \text { pero menor } 0 \\
\text { igual que } 18\end{array}$ & Mayor que 18 \\
\hline $\begin{array}{l}\text { Número de informes sobre rendición de cuentas presentados y } \\
\text { aprobados por al Concejo Municipal }\end{array}$ & Menor 0 igual que 12 & $\begin{array}{l}\text { Mayor que } 12 \text { pero menor } 0 \\
\text { igual que } 18\end{array}$ & Mayor que 18 \\
\hline $\begin{array}{l}\text { Número de programas de radio y televisión en que las autori- } \\
\text { dades municipales participaron para rendir cuentas por cada } \\
10.000 \text { habitantes }\end{array}$ & Menor 0 igual que 12 & $\begin{array}{l}\text { Mayor que } 12 \text { pero menor } 0 \\
\text { igual que } 18\end{array}$ & Mayor que 18 \\
\hline $\begin{array}{l}\text { Visitas realizadas a la sección de la página web utilizada para } \\
\text { rendir cuentas }\end{array}$ & Menor o igual que un 50\% & $\begin{array}{l}\text { Mayor que } 50 \% \text { pero menor } \\
\text { o igual que } 75 \%\end{array}$ & Mayor que $75 \%$ \\
\hline $\begin{array}{l}\text { Porcentaje de funcionarios municipales que tienen procesos } \\
\text { iniciados por actos que lesionan el interés público }\end{array}$ & Mayor que 2\% & $\begin{array}{l}\text { Mayor que } 0 \text { pero menor } 0 \\
\text { igual que } 2 \%\end{array}$ & Menor 0 igual que 0 \\
\hline $\begin{array}{l}\text { Cantidad de quejas por cada } 10.000 \text { habitantes relacionadas } \\
\text { con la ética en la función pública }\end{array}$ & Mayor o igual que 150 & $\begin{array}{l}\text { Mayor que } 100 \text { pero menor } \\
\text { que } 150\end{array}$ & Menor o igual que 100 \\
\hline $\begin{array}{l}\text { Número de solicitudes de información tramitadas oportuna- } \\
\text { mente }\end{array}$ & Menor que $90 \%$ & $\begin{array}{l}\text { Menor que } 100 \text { pero mayor } \\
\text { o igual que } 90 \%\end{array}$ & Mayor o igual que $100 \%$ \\
\hline $\begin{array}{l}\text { Porcentaje de cumplimiento con las recomendaciones de } \\
\text { órganos de supervisión nacionales }\end{array}$ & Menor que $90 \%$ & $\begin{array}{l}\text { Menor que } 100 \text { pero mayor } \\
\text { o igual que } 90 \%\end{array}$ & Mayor 0 igual que $100 \%$ \\
\hline $\begin{array}{l}\text { Porcentaje de cumplimiento con las recomendaciones de los } \\
\text { órganos de supervisión internos }\end{array}$ & Menor que $90 \%$ & $\begin{array}{l}\text { Menor que } 100 \text { pero mayor } \\
\text { o igual que } 90 \%\end{array}$ & Mayor 0 igual que $100 \%$ \\
\hline $\begin{array}{l}\text { Organizaciones de la sociedad civil del cantón que participan en } \\
\text { el monitoreo de la gestión pública }\end{array}$ & Menor que 20\% & $\begin{array}{l}\text { Menor que el } 30 \% \text { pero } \\
\text { mayor o igual que el } 20 \%\end{array}$ & $\begin{array}{l}\text { Mayor o igual que el } \\
30 \%\end{array}$ \\
\hline
\end{tabular}

Fuente: Elaboración propia, 2012 


\section{G. Administración financiera}

NIVEL DE LOS INDICADORES CUANTITATIVOS SOBRE ADMINISTRACIÓN FINANCIERA

\begin{tabular}{|c|c|c|c|}
\hline Indicador & Nivel básico & Nivel intermedio & Nivel avanzado \\
\hline $\begin{array}{l}\text { Recaudación de ingresos propios respecto de lo presu- } \\
\text { puestado }\end{array}$ & Menor de $90 \%$ & $\begin{array}{l}\text { Mayor que } 90 \% \text { pero menor } \\
\text { que } 100 \%\end{array}$ & Mayor que 100\% \\
\hline Ingresos propios por habitante & $\begin{array}{l}\text { Menor a un 33\% del salario } \\
\text { mínimo legal de un trabaja- } \\
\text { dor no calificado }\end{array}$ & $\begin{array}{l}\text { Mayor que un } 33 \% \text { del salario } \\
\text { mínimo legal de un trabajador } \\
\text { no calificado pero menor que } \\
\text { el } 66 \%\end{array}$ & $\begin{array}{l}\text { Mayor que un 66\% del } \\
\text { salario mínimo legal } \\
\text { de un trabajador no } \\
\text { calificado }\end{array}$ \\
\hline Ingresos propios por funcionario municipal & $\begin{array}{l}\text { Menor que } 2,5 \text { veces el } \\
\text { salario único del Contralor } \\
\text { General de la República }\end{array}$ & $\begin{array}{l}\text { Mayor que } 2,5 \text { veces pero } \\
\text { menor que } 4 \text { veces el salario } \\
\text { único del Contralor General de la } \\
\text { República }\end{array}$ & $\begin{array}{l}\text { Mayor que } 4 \text { veces } \\
\text { el salario único del } \\
\text { Contralor General de la } \\
\text { República }\end{array}$ \\
\hline $\begin{array}{l}\text { Impuesto de bienes inmuebles sobre unidades habitacio- } \\
\text { nales }\end{array}$ & $\begin{array}{l}\text { Menor a un } 15 \% \text { del salario } \\
\text { mínimo legal de un trabaja- } \\
\text { dor no calificado }\end{array}$ & $\begin{array}{l}\text { Mayor que un } 15 \% \text { del salario } \\
\text { mínimo legal de un trabajador } \\
\text { no calificado pero menor que } \\
\text { el } 30 \%\end{array}$ & $\begin{array}{l}\text { Mayor que un 30\% del } \\
\text { salario mínimo legal } \\
\text { de un trabajador no } \\
\text { calificado }\end{array}$ \\
\hline Ejecución de egresos respecto de lo presupuestado & Menor de 0,60 & $\begin{array}{l}\text { Mayor que } 0,60 \text { pero menor } \\
\text { que } 0,80\end{array}$ & Mayor que 0,80 \\
\hline $\begin{array}{l}\text { Egresos destinados a la prestación de servicios comuni- } \\
\text { tarios }\end{array}$ & Menor que 0,50 & $\begin{array}{l}\text { Mayor que } 0,50 \text { pero menor } \\
\text { que } 0,70\end{array}$ & Mayor que 0,70 \\
\hline Egresos destinados a la administración municipal & Mayor que 0,50 & $\begin{array}{l}\text { Mayor } 0 \text { igual que } 0.30 \text { pero } \\
\text { menor que } 0.50\end{array}$ & Menor que 0,30 \\
\hline Total gasto ejecutado por habitante del cantón & $\begin{array}{l}\text { Menor a un 30\% del salario } \\
\text { mínimo legal de un trabaja- } \\
\text { dor no calificado }\end{array}$ & $\begin{array}{l}\text { Mayor que un } 30 \% \text { del salario } \\
\text { mínimo legal de un trabajador } \\
\text { no calificado pero menor que } \\
\text { el } 60 \%\end{array}$ & $\begin{array}{l}\text { Mayor que un 60\% del } \\
\text { salario mínimo legal } \\
\text { de un trabajador no } \\
\text { calificado }\end{array}$ \\
\hline $\begin{array}{l}\text { Gasto ejecutado en prestación de servicios comunitarios } \\
\text { por habitante del cantón }\end{array}$ & $\begin{array}{l}\text { Menor a un } 20 \% \text { del salario } \\
\text { mínimo legal de un trabaja- } \\
\text { dor no calificado }\end{array}$ & $\begin{array}{l}\text { Mayor que un } 20 \% \text { del salario } \\
\text { mínimo legal de un trabajador } \\
\text { no calificado pero menor que } \\
\text { el } 30 \%\end{array}$ & $\begin{array}{l}\text { Mayor que un 30\% del } \\
\text { salario mínimo legal } \\
\text { de un trabajador no } \\
\text { calificado }\end{array}$ \\
\hline $\begin{array}{l}\text { Gasto ejecutado en prestación de servicios comunitarios } \\
\text { por unidad habitacional }\end{array}$ & $\begin{array}{l}\text { Menor a un } 66 \% \text { del salario } \\
\text { mínimo legal de un trabaja- } \\
\text { dor no calificado }\end{array}$ & $\begin{array}{l}\text { Mayor que un } 66 \% \text { del salario } \\
\text { mínimo legal de un trabajador } \\
\text { no calificado pero menor que } \\
\text { el } 100 \%\end{array}$ & $\begin{array}{l}\text { Mayor que un } 100 \% \\
\text { del salario mínimo legal } \\
\text { de un trabajador no } \\
\text { calificado }\end{array}$ \\
\hline
\end{tabular}

Fuente: Elaboración propia, 2012. 


\title{
Anexo 2
}

Niveles de gestión para indicadores cuantitativos

\section{A. Servicio al contribuyente}

\author{
TABLA 12
}

INDICADORES CUALITATIVOS DE SERVICIO AL CONTRIBUYENTE

\begin{tabular}{|l|l|l|l|l|l|}
\hline \multicolumn{1}{|c|}{ Factor } & \multicolumn{3}{|c|}{ Clasificaciones } \\
\hline 1. Se realizan en forma regular encuestas de satisfacción del contribuyente por los servicios que recibe & & & \\
\hline 2. Los funcionarios muestran cortesía, amabilidad y respeto al atender a los ciudadanos, aún en circunstancias difíiles & & & \\
\hline 3. Existe flexibilidad para atender las necesidades del contribuyente cuando estas no están previamente & & & \\
\hline definidas en un manual o es la primera vez que se presentan & & & \\
\hline 4. La institución tiene una estratégica para el desarrollo de los sistemas de información. & & & \\
\hline 5. Las instalaciones físicas tienen una apariencia moderna y pulcra. & & & \\
\hline
\end{tabular}

Fuente: Elaboración propia, 2012.

\section{B. Política de recursos humanos}

TABLA 13

\section{INDICADORES CUALITATIVOS DE POLÍTICA DE RECURSOS HUMANOS}

\begin{tabular}{|l|l|l|l|l|l|}
\hline \multicolumn{1}{|c|}{ Factor } & \multicolumn{3}{|c|}{ Clasificaciones } \\
\hline 1. Existen mecanismos para evaluar el desempeño de los funcionarios en una forma regular & & & \\
\hline 2. Existen procedimientos para asegurar que el personal esté en un proceso continuo de aprendizajey capacitación. & & & & \\
\hline 3. Existen procedimientos para asegurar que existe personal idóneo en cada posición. & & & \\
\hline 4. Existen mecanismos para evaluar y mejorar el ambiente laboral. & & & \\
\hline 5. Existen manuales de puestos que describan las responsabilidades de cada persona y los requisitos para & & & \\
\hline optar por la posición. & & & \\
\hline $\begin{array}{l}\text { 6. Existen procedimientos para asegurar que se ofrecen opciones de capacitación adecuadas para las nece- } \\
\text { sidades de la comunidad }\end{array}$ & & & & \\
\hline
\end{tabular}

Fuente: Elaboración propia, 2012. 


\section{Sistemas de información}

\section{TABLA 14 \\ INDICADORES CUALITATIVOS DE SISTEMAS DE INFORMACIÓN}

\begin{tabular}{|l|l|l|l|l|l|l|}
\hline \multicolumn{1}{|c|}{ Factor } & \multicolumn{3}{|c|}{ Clasificaciones } \\
\hline \begin{tabular}{l|l|l|l|}
\hline \multicolumn{1}{|c|}{ 1. Los sistemas de información permiten colectar información de relevancia para la toma de decisiones } \\
políticas
\end{tabular} & & & \\
\hline $\begin{array}{l}\text { 2. Existen políticas de respaldo y sistemas paralelos para asegurar la continuidad de la operación. } \\
\text { 3. Existen políticas de auditoría informática que se ejecuten en una forma regular }\end{array}$ & & & \\
\hline 4. La institución tiene una estratégica para el desarrollo de los sistemas de información. & & & \\
\hline
\end{tabular}

Fuente: Elaboración propia, 2012.

\section{Planificación estratégica}

TABLA 15

\section{INDICADORES CUALITATIVOS DE PLANIFICACIÓN ESTRATÉGICA}

\begin{tabular}{|l|l|l|l|l|l|}
\hline \multicolumn{1}{|c|}{ Factor } & \multicolumn{2}{|c|}{ Clasificaciones } \\
\hline 1. Existe un proceso de planificación estratégica que defina objetivos y metas en el largo plazo. & & & \\
\hline 2. Existe un procedimiento formal de planificación operativa que defina objetivos metas y planes de acción. & & & \\
\hline 3. Se realiza una evaluación de riesgos instituciones & & & \\
\hline 4. Se realiza un análisis FODA para analizar el entorno interno y externo & & & \\
\hline 5. Las fuerzas vivas de la comunidad participan activamente en la formulación del Plan Estratégico & & & \\
\hline
\end{tabular}

Fuente: Elaboración propia, 2012. 
E. Transparencia de la gestión

TABLA 16

INDICADORES CUALITATIVOS DE TRANSPARENCIA

\begin{tabular}{|l|l|l|l|l|l|}
\hline \multicolumn{1}{|c|}{ Factor } & \multicolumn{3}{|c|}{ Clasificaciones } \\
\hline \multicolumn{1}{|c|}{ F. Los funcionarios municipales muestran equidad, decoro y honestidad en todas sus labores } & & \\
\hline 2. Existe un Código de Ética que es ampliamente conocido por todos los funcionarios. & & & \\
\hline $\begin{array}{l}\text { 3. Los funcionarios llegan a trabajar en forma puntual, toman solo el tiempo permitido para los descansosy } \\
\text { muestran responsabilidad hacia sus funciones }\end{array}$ & & & \\
\hline $\begin{array}{l}\text { 4. Se hace todo esfuerzo necesario para llegar a las comunidades más distantes con información sobre la } \\
\text { rendición de cuentas }\end{array}$ & & & \\
\hline
\end{tabular}

Fuente: Elaboración propia, 2012.

\section{F. Política de control gerencial y administración financiera}

Las políticas de control gerencial, se evalúan con base en la siguiente lista de indicadores cualitativos:

TABLA 17

INDICADORES CUALITATIVOS DE CONTROL GERENCIAL

\begin{tabular}{|l|l|l|l|l|}
\hline \multicolumn{1}{|c|}{ Factor } & \multicolumn{3}{|c|}{ Clasificaciones } \\
\hline 1. Existen procedimientos formales para determinar los niveles de riesgo operativo y financiero. & & & \\
\hline 2. Existen procedimientos para el control operativo de cada departamento & & & \\
\hline 3. Existen procedimientos formales para el control presupuestario. & & & \\
\hline 4. Existen procedimientos para facilitar la presentación de denuncias de fraude y malversación de fondos. & & & \\
\hline 5. Existe una Contraloría de Servicios que sea funcional y que atienda en un horario regular & & & \\
\hline 6. Existe un Departamento de Auditoría Interna que sea funcional & & & \\
\hline 7. Se sigue siempre un procedimiento previamente definido y legalmente apropiado para aprobar todas las & & & \\
\hline erogaciones de recursos & & & \\
\hline
\end{tabular}

Fuente: Elaboración propia, 2012. 